\title{
A Human Lung Challenge Model to Evaluate the Safety and Immunogenicity of PPD and Live BCG
}

*Malika Davids ${ }^{1}$, *Anil Pooran ${ }^{1}$, Clemens Hermann², Lynelle Mottay ${ }^{1}$, Fawziyah Thompson ${ }^{1}$, Jacob Cardenas $^{3}$, Jinghua Gu ${ }^{3}$, Thearith Koeuth ${ }^{3}$, Richard Meldau ${ }^{1}$, Jason Limberis ${ }^{1}$, Phindile Gina ${ }^{1}$, Shashikant Srivastava ${ }^{3}$, Bridget Calder $^{2}$, Aliasgar Esmail ${ }^{1}$, Michele Tomasicchio ${ }^{1}$, Jonathan Blackburn², Tawanda Gumbo ${ }^{3}$, and Keertan Dheda ${ }^{1,4}$.

*Authors contributed equally; joint first authors

${ }^{1}$ Centre for Lung Infection and Immunity, Division of Pulmonology, Department of Medicine and UCT Lung Institute \& South African MRC/UCT Centre for the Study of Antimicrobial Resistance, University of Cape Town, Cape Town, South Africa.

${ }^{2}$ Department of Integrative Biomedical Sciences, Institute of Infectious Disease \& Molecular Medicine, Faculty of Health Sciences, University of Cape Town, Anzio Road Observatory, Cape Town 7925, South Africa.

${ }^{3}$ Baylor Institute for Immunology Research, 53620, Dallas, Texas, United States.

${ }^{4}$ Faculty of Infectious and Tropical Diseases, Department of Immunology and Infection, London School of Hygiene and Tropical Medicine, London, UK.

\section{Corresponding author:}

Keertan Dheda

\section{$\underline{\text { Keertan.dheda@uct.ac.za }}$}

Division of Pulmonology \& UCT Lung Institute, Department of Medicine

Old Main Building, Observatory 7439, Cape Town, South Africa 
Authors contributions: Study concept and design: MD, AP, JB, TG and KD; patient recruitment: LM, PG, and AE ; laboratory work: MD, AP, CH, FT, JC, JG, TK, RM, JL, SS, BC, and MT; analysis and interpretation: MD, AP, CH, FT, JC, JG, TK, RM, JL, SS, BC, MT, JB, TG, and KD; drafting of manuscript: MD, AP, CH, FT, JC, JG, TK, RM, JL, SS, BC, MT, JB, TG, LM, PG, AE, and KD. All authors gave important intellectual input.

Short running head: A lung-orientated human infection model for TB

Word count for manuscript body $=4055$

This article has an online data supplement, which is accessible from this issue's table of content online at www.atsjournals.org. 


\begin{abstract}
Background: A human model to better understand tuberculosis immunopathogenesis and facilitate vaccine development is urgently needed. We evaluated the feasibility, safety, and immunogenicity of live Bacille-Calmette-Guerin (BCG) in a lung-orientated controlled human infection model.
\end{abstract}

Methods: We recruited 106 healthy South African participants with varying degrees of tuberculosis susceptibility. Live BCG, sterile purified-protein-derivative (PPD), and saline were bronchoscopically instilled into separate lung segments $(n=65)$. A control group $(n=34)$ underwent a single bronchoscopy without challenge. The primary outcome was safety. Cellular and antibody immune signatures were identified in broncho-alveolar lavage fluid before, and three days after challenge using flow cytometry, ELISA, RNA sequencing and mass spectrometry.

Findings: The frequency of adverse events was low $(9.4 \% ; n=10)$, similar in the challenge versus control groups $(\mathrm{p}=0.8)$, and were all mild and managed conservatively in an outpatient setting. The optimal PPD and BCG dose was 0.5 Tuberculin units, and $10^{4}$ colony-forming units (CFU), respectively, based on changes in BAL cellular profiles $(p=0.02)$ and antibody responses $(p=0.01)$ at incremental doses pre- versus post-challenge. At $10^{4}$, versus $10^{3} \mathrm{CFU}$ of BCG, there was a significant increase in number differentially expressed genes (367 versus $3 ; \mathrm{p}<0.001)$ and dysregulated proteins $(64$ versus $0 ; \mathrm{p}<0.001)$. Immune responses were highly setting-specific (in-vitro versus in-vivo), compartmentspecific (BAL versus blood), and were localised to the challenged lung segments.

Conclusion: A lung-orientated mycobacterial controlled human infection model using live BCG and PPD is feasible and safe. These data inform the study of TB immunopathogenesis and strategies for evaluation and development of TB vaccine candidates. 
Word count $=\mathbf{2 5 0}$

\section{At a Glance}

Scientific knowledge on the subject: Murine and non-human primate mycobacterial lung challenge models, using either BCG or M. tuberculosis, have provided valuable insights into tuberculosis (TB) immunopathogenesis at the site of disease. However, human studies using BCG and/or PPD lung challenge are limited. There are no published human lung challenge studies using PPD or live BCG in different clinical phenotypes and from a TB-endemic setting. The feasibility, safety, and optimal dose of BCG in this context remains to be clarified.

What this study adds to the field: This 'first-in-man study' demonstrates that bronchoscopic instillation of live BCG and PPD into the lungs of healthy participants, representing a gradient of TB susceptibility, is safe and feasible when performed in a TB endemic setting. Several BCG and PPD doses were evaluated and the minimal safest immunogenic dose identified. These data demonstrate the safety and feasibility of a lungorientated mycobacterial human infection model and provide a solid foundation for the advancement of several lines of research including (i) the study TB immunopathogenesis, (ii) identification of biosignatures of TB risk, (iii) development of better models to evaluate vaccine efficacy, and (iv) optimising the route of vaccine delivery (respiratory tract versus intradermal). 


\section{INTRODUCTION}

Tuberculosis (TB) is now the foremost infectious disease killer globally(1). Finding an effective vaccine represents the best hope for effective disease control but success has been limited. For example, MVA85A showed no added benefit over BCG in a phase IIb clinical trial(2) and more recently M72/AS01 exhibited a vaccine efficacy of only $\sim 50 \%$ compared to a placebo(3). By contrast, measles and polio vaccines have an efficacy of more than $90 \%(4$, 5). The only currently licensed TB vaccine, BCG, is an attenuated strain of Mycobacterium bovis (M.bv) [both BCG and M.bv are part of the Mycobacterium tuberculosis complex (MTBC)]. Active disease due to the wild type M.bv, and sometimes even BCG $(6,7)$, results in human TB indistinguishable from that produced by the human pathogen $M$. tuberculosis (M.tb). BCG protective efficacy in adults against active TB is only $\sim 30 \%(8)$ but is still used globally because it reduces the burden of disseminated and meningeal forms of the disease in children $(9,10)$. BCG has $>99 \%$ sequence homology to M.tb at nucleotide level, predominantly differing by a 9.5-kb deletion of region-of-difference-1 (RD1) (11-14). Animal and non-human primate (NHP) studies show improved BCG efficacy when administered via the intrapulmonary route $(15,16)$. However, whether this is true in humans remains unclear. This is an important question because even a marginal increase in BCG efficacy, a low cost and globally available vaccine, will significantly reduce the worldwide burden of disease $(17,18)$. How should BCG efficacy be evaluated in humans?

Controlled human infection model [CHIM] studies in other global diseases such as malaria and cholera have facilitated the study of disease pathogenesis, identification of the role of key virulence factors, improved vaccine efficacy, and chemotherapy(19). Given the obvious ethical concerns such as the requirement for complex and toxic multi-drug treatment for 6months, long incubation period of several months to years, and the difficulty in confirming a 
diagnosis of active TB due to M.tb, use of BCG, which is avirulent in nonimmunosuppressed persons, could serve as a good surrogate to "simulate" M.tb infection. Access to such a mycobacterial-associated CHIM (mCHIM) will help address several key questions including better understanding TB immunopathogenesis in the human lung, the site of infection and disease. In addition, surrogates of protective immunity and TB risk remain elusive, hampering the selection of effective vaccine candidates. $\mathrm{mCHIM}$ in volunteers with different TB susceptibility profiles (ranging from sterilizing immunity to multiple previous episodes of active TB) could simplify and facilitate the prioritisation of nascent vaccine candidates (currently costs $\sim$ US\$ one billion per candidate and $\sim 15$ years for complete development and evaluation). Finally, a mCHIM would facilitate the evaluation of intra-pulmonary versus intradermal responses to BCG.

The quintessential first step in developing a lung-orientated mCHIM using live-BCG is to establish the feasibility and safety of such a model in a TB endemic country. Concerns to be allayed include the Koch phenomenon (a tuberculin reaction that occurs when persons already infected are exposed to tubercle bacilli), dose-related toxicity, and a systemic hypersensitivity reaction. To address the need for a $\mathrm{mCHIM}$ and to address other critical questions we evaluated the safety and feasibility of bronchoscopic installation of live BCG, and sterile purified-protein-derivative (PPD), in healthy South African participants categorized into clinical phenotypes (based on clinical, radiological and immunodiagnostic parameters) likely representing a gradient of TB susceptibility. Our secondary goal was to determine the optimal dose (or inoculum) of PPD and BCG that could be safely administered into the lung to produce a measurable cellular response. This foundational information could then be used to validate a mCHIM and design studies to address questions surrounding optimal route of vaccination, mycobacterial immuno-pathogenesis, biomarkers of risk and 
protection, and as a comparative reference standard against which potential vaccine candidates could be evaluated.

\section{METHODS}

\section{Study design and participants}

The study was approved by the South African Health Products Regulatory Authority (SAHPRA; reference 20141037), and the University of Cape Town Research Ethics Committee (REC/REF 659/2014) in March 2015. All participants provided written informed consent and were compensated for time off from work and travel.

Between 23 June 2015 - 26 April 2019, we enrolled 106 BCG-vaccinated (at birth), HIVuninfected, healthy adults between 18-43 years of age in Cape Town, South Africa. Current smokers and individuals with any chronic or immunocompromising illness were considered ineligible. Participants were categorised into four sub-groups based on clinical, radiological and immunodiagnostic features, which were assumed to represent a gradient of TB susceptibility (Figure 1). Those assumed to have a "protective" phenotype i.e. "sterilizing immunity" and "latent TB infection" (LTBI) groups, were asymptomatic household contacts of an active TB case (smear positive with cavitary disease) with no history of active disease and were either interferon-gamma-release-assay (IGRA; Quantiferon-TB-Gold-Plus) negative or positive, respectively. Those assumed to have a "susceptible" phenotype included participants with either a single ("previous TB") or multiple ("recurrent TB") episodes of microbiologically proven (smear, Xpert MTB/RIF or MGIT culture positive) drug-sensitive $\mathrm{TB}$, respectively, and had completed a full course of anti-TB treatment at least six months prior to recruitment. All participants underwent a chest X-ray (CXR) and safety blood screening, including international normalized ratio, full blood count, and clinical chemistry (creatinine, bilirubin, ALT) at the time of enrollment. 


\section{Preparation of BCG and PPD}

Both PPD and BCG dilutions were prepared from GMP-grade pharmaceutical stocks under sterile conditions. Additional details are provided in the online supplement section 1.1 and 1.2 .

\section{Bronchoscopic installation of saline, BCG and PPD}

A baseline bronchoscopy and broncho-alveolar lavage (BAL) was performed in the right middle lobe (RML). Fifteen $\mathrm{ml}$ of BCG and PPD suspensions and of $0.9 \%$ saline were then instilled into the distinct lung segments. The participant returned 3 days after this initial procedure and a repeat bronchoscopy was performed at the site of BCG, PPD and sterile saline instillation. An aliquot of BAL retrieved from the BCG-challenged lung segment was cultured using Bactec MGIT (BD) when sufficient sample was available. Additional details are provided in the online supplement section 1.3.

\section{Laboratory procedures}

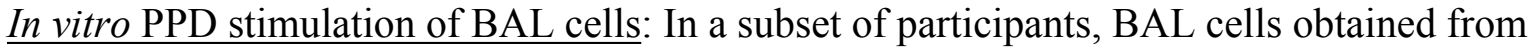
the baseline bronchoscopy were cultured $\left(\sim 1 \times 10^{6}\right)$ cells in 24 -well plates and stimulated with PPD $(12 \mu \mathrm{g} / \mathrm{ml})$ for three days. This in vitro PPD stimulation was performed to directly compare the cellular phenotypes and cytokine expression to BAL cells retrieved from the PPD challenged segment (in vivo challenge).

Flow cytometry analysis: BAL cells and peripheral whole blood $(200 \mu 1)$ collected at baseline and three-days post lung challenge were enumerated and stained $\left(\sim 1 \times 10^{6}\right.$ cells for BAL cells) with fluorescently conjugated antibodies for specific cell surface [CD3, CD4, CD8, CD25, CD69, TLR-2 (BD BioSciences, USA), CD19, CD83, CD56, HLA-DR (BD BioSciences, USA), CD66b] and intracellular [perforin, granulysin, IFN- $\gamma$, TNF- $\alpha$, IL-17, 
IL-13, IL-9, and NGAL (Hycult Biotech, The Netherlands) markers], as previously described (20). All other antibodies were purchased from Biolegend (Biolegend, USA).

Antibody levels: Total protein concentration was determined using a BCA kit (Thermo Fisher Scientific) whereas antibody levels for IgG and IgA were determined by ELISA (Ebiosciences, USA), in BAL supernatant pre- and post-lung challenge.

Proteomic analysis: BAL supernatant was processed and underwent proteomic analysis using a Q Exactive mass spectrometer (Thermo Fisher Scientific). Additional details are provided in the online supplement sections $1.5-1.8$.

Transcriptomic analysis: An aliquot of pre- and post-lung challenge BAL cells were immediately stored in RNALater (Qiagen). RNA was then extracted and sequenced, and quality controls performed as described in detail in our prior publication(21). Differentially expressed genes [DEGs] were defined by comparing pre- and post-BCG or PPD or saline instillation, using a false discovery rate $\mathrm{p}<0.05$, across multiple comparisons. Additional details are provided in the online supplement section 1.9.

\section{Outcomes}

The primary outcome measure of safety was assessed by comparing the frequency of adverse events (AEs) between challenged and non-challenged participants and the possible causal relationship between AEs and the instillation of BCG and PPD. Severity of the AEs were graded based on the DAIDS guidelines and were classified as anticipated or unanticipated (AEs not commonly associated with the bronchoscopy procedure).

The optimal dosage of PPD and BCG that could be safely administered in the lung to produce a measurable cellular response was also investigated. PPD and BCG-specific cell numbers, cell types, the number of differentially expressed genes and dysregulated proteins 
(at the different BCG concentrations), cytokine responses and antibody levels (IgG and IgA) were determined in the cells and supernatant retrieved from BAL pre- and post-lung challenge. Responses were normalized to the volume of BAL fluid retrieved and compared to the baseline BAL. Comparisons were also made to the saline only instillation control.

\section{Sample size calculations and statistical analysis}

For immuno-phenotyping, proteomics and transcriptomic analysis at least 6 participants per group were necessary to detect the smallest estimated 2-fold change in specific biomarker expression between the groups for $70 \%$ power and $95 \%$ confidence. Statistical analyses were performed using GraphPad Prism version 6.0 (Graphpad software). Methods are provided in the online supplement.

\section{RESULTS}

\section{Clinical characteristics of study participants}

We screened a total of 870 healthy adults and enrolled 106 participants who underwent a bronchoscopy procedure (Figure 1). The baseline demographics and clinical parameters did not significantly differ between the different participant groups: sterilizing immunity, latent TB infection (LTBI), previous TB, and recurrent TB (Table 1).

\section{Frequency of adverse events}

In order to "abstain from doing harm", especially from delayed hypersensitivity reactions to BCG and PPD (pulmonary "Koch phenomenon"), the first five study participants undergoing lung challenge were monitored in hospital. None of them developed a hypersensitivity reaction during hospitalization. After discharge they were contacted daily for the first week 
post-challenge, then weekly until 30-days post procedure. None of them experienced any significant adverse events. Further recruitment was only performed after this.

The frequency of unanticipated adverse events [AEs] in all 106 participants was 8/74 (11\%) in challenge group versus $2 / 32(6 \%)$ in controls $(p=0.8)$ and a relative risk of $1.15[95 \%$ confidence interval: 0.70-1.48], as shown in Figure 2 and online supplement table S1. The AEs were not severe and required only conservative clinical intervention. The adverse events had a possible [7/10 participants (70\%); Table 2] causal link to the bronchoscopy procedure, but none were found to have a causal relationship to the instillation of either BCG or PPD themselves (Table 2). The adverse events commonly associated with the bronchoscopy procedure included sore throat, shortness of breath, chest pains, cough, and fever. Importantly, approximately $90 \%$ of these adverse events resolved within seven days post procedure, and all were resolved within 14 days (Table 2).

\section{Bronchoscopy controls}

Given the force of saline movement within a lung segment and resulting mechanical shearing of cells in the airway we performed a series of saline-only installation experiments to assess the impact of the procedure itself to produce a lung cellular response. A baseline bronchoscopy was performed on day zero, followed by installation with $15 \mathrm{ml}$ of $0.9 \%$ saline into three different lung segments (the same volume to be used for BCG and PPD challenge) of four healthy volunteers. A repeat bronchoscopy was performed three days later at the saline instillation sites. We found no significant differences in the number of cells per $\mathrm{ml}$ of BAL fluid obtained pre- and post-saline instillation (Figure 3A). Moreover, no significant changes in the expression of biomarkers associated with cytotoxicity (frequency of $\mathrm{CD}^{+}{ }^{+}$Perforin ${ }^{+}$Granulysin ${ }^{+}$; Figure 3B; $\mathrm{p}=0.7$ ), IFN- $\gamma$ expression by $\mathrm{CD} 4^{+}$cells (Figure $3 \mathrm{C}$, $p=0.26$ ), and T-cell activation (Figure $3 \mathrm{D}, \mathrm{p}=0.32$ ). 
All participants who underwent the lung challenge procedure with live BCG and sterile PPD also received a concurrent saline instillation in a separate lung segment. These data suggested that the immune response to PPD and BCG is localised to the specific lung segment into which it is instilled. Thus, the immunological response of the saline-only lung segment showed a similar immunological response (online supplement Figure S1), transcriptomic profile (Figure S2) and protein profile (Figure S3) to the baseline bronchoscopy.

\section{BCG dosage optimisation}

We performed BCG optimisation in participants with a history of prior TB using three different inocula (or doses) of live $\mathrm{BCG}\left(10^{2}, 10^{3}\right.$, and $\left.10^{4} \mathrm{CFU}\right)$. We found a significant increase in cell numbers in the challenged lung segments only at the higher BCG dose of $10^{4}$ $\mathrm{CFU}$ (Figure 4A, $\mathrm{p}=0.04$ ). We observed the greatest immunological changes at $10^{4} \mathrm{CFU}$, compared to the baseline bronchoscopy, in terms of (i) cellular phenotype [decreased macrophages $(p=0.02)$, increased neutrophils ( $p=0.03$ ), Figure 4B]; (ii) antibody responses [increased IgG levels, $p=0.01$, Figure 4C and D]; (iii) the number of DEGs (367 DEGs at BCG $10^{4}$ CFU versus 3 DEGs at BCG $10^{3}$ CFU versus 3 DEGs at BCG $10^{2} \mathrm{CFU}$; $\mathrm{p}<0.001$; Figure 4E), (iv) higher host protein expression (64 dysregulated proteins identified at BCG $10^{4} \mathrm{CFU}$ versus 0 at $\mathrm{BCG} 10^{3}$ and 1 at $10^{2} \mathrm{CFU} ; \mathrm{p}<0.001$; Figure $4 \mathrm{~F}$ ) and extent of protein dysregulation in the BAL fluid (identified by mass spectrometry, Figure S4 in the online supplement).

Additionally, a BCG BAL fluid sample was sent for culture in a subgroup of participants $(n=54)$ and, of these participants, only 6 had a positive culture result $(11 \%$, Table S2 online supplement). 


\section{PPD dosage optimisation}

We initially tested two different PPD doses (0.2 TU and 0.5TU) intradermally in 21 healthy participants with a history of BCG vaccination ("primum non nocere"). We found no significant changes in the size of induration three days after intradermal challenge (Figure $5 \mathrm{~A}, \mathrm{p}=0.49, \mathrm{n}=21$ ), and no Koch phenomenon. With that reassurance, we instilled 0.5 TU PPD into lung segments of these participants. There was no delayed hypersensitivity. This $0.5 \mathrm{TU}$ resulted in (i) increased antibody responses (increased IgG and IgA levels, $p=0.007$, $p=0.008$ respectively, Figure 5B-C); (ii) increased cell numbers in the challenged lung segment (figure 5D, $\mathrm{p}=0.015$ ), and changes in (iii) cellular phenotype [decreased macrophages ( $p=0.03)$, increased T-cells $(p=0.01)$, Figure 5E]; and (iv) cytokine expression profiles [increased $\mathrm{CD} 4^{+} \mathrm{IFN}-\gamma(\mathrm{p}=0.015)$ and decreased $\mathrm{CD} 4^{+} \mathrm{CCR} 6^{+} \operatorname{IL} 17^{+}(\mathrm{p}=0.015)$, Figure 5F].

\section{Immune responses in the lung versus the peripheral blood}

Comparison of biomarker expression in the lung and peripheral blood at baseline indicated a compartment specific effect, i.e. the level of expression in lung was significantly different to that in the peripheral blood. For example, we found significantly higher levels of CD4 ${ }^{+}$IFN$\gamma^{+}$(figure 6A, p<0.01), CD4 $4^{+} \mathrm{IL}_{-} 9^{+}$(figure 6A, $\mathrm{p}<0.01$ ), $\mathrm{CD}^{+} \mathrm{IL}_{-1} 3^{+}$(figure 6A, $\mathrm{p}<0.001$ ), and $\mathrm{CD}^{+} \mathrm{CCR}^{+} \mathrm{IL} 7^{+}$(figure $6 \mathrm{~A}, \mathrm{p}<0.01$ ) in BAL cells compared to cells in peripheral blood. Next, we found that in vivo stimulation with PPD yielded a different immunological response compared to in vitro PPD stimulation. In vivo stimulation resulted in significantly less expression of haemoxygenase by macrophages (figure $6 \mathrm{~B}, \mathrm{p}=0.04$ ), myeloid-derived suppressor cells (figure 6B, $\mathrm{p}=0.001$ ), and $\mathrm{CD}^{+} \mathrm{Caspase}^{+}$(figure 6B, $\mathrm{p}=0.02$ ). 


\section{DISCUSSION}

This is the first study to undertake bronchoscopic instillation of live BCG and sterile PPD into the lungs of humans with different immune phenotypes likely representing a gradient of TB susceptibility. The key findings of the study were that (i) pulmonary administration of live $\mathrm{BCG}$, and sterile PPD, even in those with previous active $\mathrm{TB}$, is safe and feasible and is only associated with infrequent and non-severe AEs; (ii) $10^{4}$ CFU of BCG and 0.5 TU of PPD were the lowest possible doses that induced a detectable lung mucosal-specific immune responses; (iii) pulmonary immune responses to antigenic challenge were highly localised within a lung segment (not generalized across the entire lung) and antigen-dependent (BCG and PPD produced markedly different responses both in magnitude and immunotype), and (iv) immune responses were highly compartmentalised (lung versus blood) and modeldependent (in vitro versus in vivo). Using a control group enabled us to demonstrate that most of the AEs observed were a consequence of the bronchoscopy procedure rather than the BCG or PPD lung challenge.

We have demonstrated the safety of lung installation of live BCG and sterile PPD at doses high enough to produce reliably detectable responses. We designed the study to specifically evaluate the risk of AEs (such as hypersensitivity reactions that Koch first described) that would occur in BCG-vaccinated participants with a history of prior TB. Additionally, given the extent of TB sensitization in this specific participant group (i.e. previous TB) we hypothesized that these participants should have a robust immunological recall response to lung challenge with PPD and/BCG. Thus, all PPD and BCG dose-related experiments were performed on participants with previous history of TB. Mucosal delivery of up to 4-8 $\times 10^{8}$ BCG CFUs as adjuvant local therapy for lung and bladder cancer lead to prolonged fevers in PPD skin-reactive patients; these high doses were given with the intent to stimulate a 
therapeutic inflammatory reaction enough to slough off the cancerous cells(22, 23). In 1968, Rosenthal and colleagues gave nebulized BCG as an infection challenge followed by a tuberculin skin test(24). However, they could not confirm that the BCG reached the alveoli in any reproducible manner and they did not standardise the inhaled dosage. Thus, ours is the first study to directly deliver BCG into the lungs of healthy participants with a spectrum of TB susceptibility, and to study lung-specific immunity in this context.

The optimal dose of intrapulmonary BCG needed clarification. We were only able to detect a robust immunological response (transcriptomic, proteomic, and cellular), and significant cellular influx into the lungs at $10^{4} \mathrm{CFU}$ Rather than $\leq 10^{3} \mathrm{CFU}$ ). We also optimised the dose of PPD, which contains high concentrations of the complete M.tb antigenic repertoire (rather than the surface repertoire displayed by BCG), including RD1 proteins(25). We detected a reliable immunological response in the lung after instilling 0.5 TU PPD. Indeed, Silver et al found that bronchoscopic lung challenge with 0.5 TU PPD drove an antigen specific IFN- $\gamma$ CD4 T-cell response in PPD responders in a low burden setting(26), and that the IFN- $\gamma$ production was predominantly secreted by effector memory cells (27). We showed a similar pattern of lymphocytic infiltration and increase in CD4 Tcells expressing IFN- $\gamma$ following PPD challenge (Figure 5). Surprisingly, both in PPD and BCG challenged participants, the frequency of Th17 homing cells $\left(\mathrm{CD} 4^{+} \mathrm{CCR} 6^{+} \mathrm{IL}-17^{+}\right)$, associated with a proinflammatory memory immune response in those with TB disease(28), decreased following challenge.

The immune responses to BCG and PPD were markedly different in terms of DEGs, proteins, and cellular abundance. There are several potential factors which may contribute to this observation including (i) antigen concentration: there are no published equivalence data but our crude spectrophotometric-based estimation of the soluble protein fraction concentration 
of BCG was $\sim 10$-fold lower than PPD; (ii) antigen repertoire: BCG is an attenuated strain of M bovis, which lacks critical virulence factors such as EAST-6 and CFP-10, and PPD is comprised mainly of soluble protein with limited polysaccharide and lipid content (25) whilst the BCG antigen repertoire will also include cell wall components (29); (iii) nature of antigen: PPD is ready for presentation on antigen-presenting cells allowing for faster initiation of adaptive immunity. Antigen-specific immune responses were also highly compartmentalised (dramatically different in magnitude and often higher in BAL versus blood). Furthermore, the segment-specific saline control (in every patient) and preliminary saline installation experiments (repeated bronchoscopy in three distinct lung lobes in a subset of individuals) demonstrated that pulmonary immune responses were highly localised within the specific lung challenged lung segment/s and that the bronchoscopy-specific mechanoinflammatory effect was minimal. In addition, in vitro (harvesting of BAL cells with threeday antigen stimulation in the laboratory) and in vivo responses (comparing the baseline to the three-day post challenge response) were dramatically different. These findings suggest that reappraisal of some of our understanding of human TB immunology would be helpful given that correlates of immunity are routinely measured using peripheral blood (systemic immunity), which do not reflect lung-compartmentalised findings (29), and the most commonly used assays involve in vitro stimulated cells from peripheral human blood. This likely means that it will be necessary to study efficacy of vaccines and identify correlates of protection that depend on sampling the lung, and infection/ vaccine challenges via the lung.

There are several implications of our findings. We have taken the foundational steps in establishing the feasibility of a mycobacterial lung-orientated CHIM (mCHIM). Other investigators can now replicate this model, which will allow several important questions to be addressed. First, it will allow us to finally begin to address the issue of the optimal route of BCG vaccination in humans (intrapulmonary versus intradermal BCG vaccination efficacy). 
This is a critical question as animal data, including non-human primates(30), suggest significantly higher efficacy with pulmonary BCG vaccination $(15,16)$ and there were higher frequencies of Ag85a-specfic CD4 T-cells in the lungs of participants receiving aerosolized MVA85A vaccine compared to intradermal administration(31). Demonstrating even a marginally higher efficacy with a low-cost safe vaccine will translate into significant reductions in disease burden. Second, mCHIM will allow us to better understand the immunopathogenesis of TB (we still don't know why some people get TB and others don't). Third, it will facilitate the identification of a biosignature synonymous with TB risk and protection, which remains a major research priority in TB for several reasons. A key advantage of our model is that it allows us to hierarchically rank immune responses along a spectrum of susceptibility in the absence of a reference standard. Fourth, mCHIM could provide a potential platform for the evaluation and prioritisation of new vaccine candidates (compared to $\mathrm{BCG}$ as a reference). Evaluation of new vaccine candidates is an incredibly long and expensive endeavour requiring large clinical trials without any guarantee of efficacy, even with promising preclinical results in animals.

There are several limitations of our study. (i) The biological relevance of our model is questionable given that BCG is not generally a pathogenic strain that causes typical TB and lacks critical virulence genes. However, using M.tb is neither ethical nor feasible, BCG has $>99 \%$ sequence homology to $M . t b$, is an attenuated strain of $M$. bovis - a causative agent of TB clinically indistinguishable from M.tb, and BCG is part of the M.tb complex and can sometimes causes clinical disease compatible with active TB (7). Furthermore, it is a live organism delivered to the disease site and better simulates what happens in humans (the comparative use of PPD also allowed us, to some extent, 'compensate' for the effect of virulence factors absent from BCG). (ii) Theoretically there could have been some cross priming, cross-contamination, or 'steal effect' between segments challenged with BCG and 
PPD. However, the saline control indicated that was unlikely and also allowed us to determine the mechanical effect of the bronchoscopy procedure itself. We also took special care to deliver antigen in a small volume of only $15 \mathrm{ml}$, followed by $60 \mathrm{ml}$ of air and thus prevented reflux from the cannulated bronchus. However, this did not exclude possible interaction between PPD and BCG in the draining lymph node. (iii) We did not evaluate long-term memory responses that would have required a longer timeframe between instillation and repeat bronchoscopy. However, on this first cut we chose to prioritise and evaluate early memory $\mathrm{T}$ cell responses. (iv) Our sample size in the subgroups were limited. However, we were well powered for safety and limited resources and funding meant that we were only able to perform small subgroup studies (even so, we could demonstrate significant inter-group differences). (v) Responses using other strains of BCG could theoretically be different to the Danish 1331 strain that we used(32), however, this remains the most commonly used strain globally. (vi) The use of general anaesthesia is considered to be very safe, but it does confer additional risk to study participants. Therefore, we have taken several precautionary steps to minimize risk including that (a) using a board-certified and accredited anaesthetist; (b) participants received a pre-anaesthetic consult by an independent anaesthetist to asses fitness for anaesthesia prior to commencing each bronchoscopy; (c) each participant was closely observed post-bronchoscopy until they recovered to pre-op state; (d) patients with specific conditions that increased associated risk were excluded (e.g. those with hypertension, high alcohol intake, history of smoking, drug allergies, diabetes, obesity, etc).

In conclusion, we have established that a mCHIM using live BCG and sterile PPD is feasible and safe in individuals from endemic countries with varying susceptibility profiles, and that $10^{4} \mathrm{CFU}$ BCG and 0.5 TU PPD is required to elicit a detectable immunological response. Further studies are now required to replicate and validate this model and use it to address several important questions related to TB immunology and vaccinology. 
Acknowledgments: We are grateful to the study participants and to the Bill Melinda Gates Foundation, and the South African MRC, for funding this work. 


\section{REFERENCES}

1. Dheda K, Barry CE, 3rd, Maartens G. Tuberculosis. Lancet 2016; 387: 1211-1226.

2. Tameris MD, Hatherill M, Landry BS, Scriba TJ, Snowden MA, Lockhart S, Shea JE, McClain JB, Hussey GD, Hanekom WA, Mahomed H, McShane H, Team MATS. Safety and efficacy of MVA85A, a new tuberculosis vaccine, in infants previously vaccinated with BCG: a randomised, placebo-controlled phase $2 \mathrm{~b}$ trial. Lancet 2013; 381: 10211028.

3. Van Der Meeren O, Hatherill M, Nduba V, Wilkinson RJ, Muyoyeta M, Van Brakel E, Ayles HM, Henostroza G, Thienemann F, Scriba TJ, Diacon A, Blatner GL, Demoitie MA, Tameris M, Malahleha M, Innes JC, Hellstrom E, Martinson N, Singh T, Akite EJ, Khatoon Azam A, Bollaerts A, Ginsberg AM, Evans TG, Gillard P, Tait DR. Phase 2b Controlled Trial of M72/AS01E Vaccine to Prevent Tuberculosis. N Engl J Med 2018; 379: 1621-1634.

4. Bandyopadhyay AS, Garon J, Seib K, Orenstein WA. Polio vaccination: past, present and future. Future Microbiol 2015; 10: 791-808.

5. Marin M, Nguyen HQ, Langidrik JR, Edwards R, Briand K, Papania MJ, Seward JF, LeBaron CW. Measles transmission and vaccine effectiveness during a large outbreak on a densely populated island: implications for vaccination policy. Clin Infect Dis 2006; 42: 315-319. 
6. Ying W, Sun J, Liu D, Hui X, Yu Y, Wang J, Wang X. Clinical characteristics and immunogenetics of BCGosis/BCGitis in Chinese children: a 6 year follow-up study. PLoS One 2014; 9: e94485.

7. Asín MAP-J, Fernández-Ruiz M, López-Medrano F, Lumbreras C, Tejido Á, San Juan R, Arrebola-Pajares A, Lizasoain M, Prieto S, Aguado JM. Bacillus Calmette-Guérin (BCG) infection following intravesical BCG administration as adjunctive therapy for bladder cancer: incidence, risk factors, and outcome in a single-institution series and review of the literature. Medicine 2014; 93.

8. Roy A, Eisenhut M, Harris R, Rodrigues L, Sridhar S, Habermann S, Snell L, Mangtani P, Adetifa I, Lalvani A. Effect of BCG vaccination against Mycobacterium tuberculosis infection in children: systematic review and meta-analysis. Bmj 2014; 349: g4643.

9. da Costa C, Walker B, Bonavia A. Tuberculosis vaccines--state of the art, and novel approaches to vaccine development. Int J Infect Dis 2015; 32: 5-12.

10. Fordham von Reyn C, Vuola JM. New vaccines for the prevention of tuberculosis. Clinical infectious diseases 2002; 35: 465-474.

11. Garnier T, Eiglmeier K, Camus J-C, Medina N, Mansoor H, Pryor M, Duthoy S, Grondin S, Lacroix C, Monsempe C. The complete genome sequence of Mycobacterium bovis. Proceedings of the National Academy of Sciences 2003; 100: 7877-7882.

12. Zhang W, Zhang Y, Zheng H, Pan Y, Liu H, Du P, Wan L, Liu J, Zhu B, Zhao G. Genome sequencing and analysis of BCG vaccine strains. PloS one 2013; 8: e71243. 
13. Gordon SV, Brosch R, Billault A, Garnier T, Eiglmeier K, Cole ST. Identification of variable regions in the genomes of tubercle bacilli using bacterial artificial chromosome arrays. Molecular microbiology 1999; 32: 643-655.

14. Mahairas GG, Sabo PJ, Hickey MJ, Singh DC, Stover CK. Molecular analysis of genetic differences between Mycobacterium bovis BCG and virulent M. bovis. Journal of bacteriology 1996; 178: 1274-1282.

15. Aguilo N, Alvarez-Arguedas S, Uranga S, Marinova D, Monzón M, Badiola J, Martin C. Pulmonary but Not Subcutaneous Delivery of BCG Vaccine Confers Protection to Tuberculosis-Susceptible Mice by an Interleukin 17-Dependent Mechanism. The Journal of infectious diseases 2015; 213: 831-839.

16. Verreck FAW, Tchilian EZ, Vervenne RAW, Sombroek CC, Kondova I, Eissen OA, Sommandas V, van der Werff NM, Verschoor E, Braskamp G, Bakker J, Langermans JAM, Heidt PJ, Ottenhoff THM, van Kralingen KW, Thomas AW, Beverley PCL, Kocken CHM. Variable BCG efficacy in rhesus populations: Pulmonary BCG provides protection where standard intra-dermal vaccination fails. Tuberculosis (Edinb) 2017; 104: 46-57.

17. Knight GM, Griffiths UK, Sumner T, Laurence YV, Gheorghe A, Vassall A, Glaziou P, White RG. Impact and cost-effectiveness of new tuberculosis vaccines in low-and middleincome countries. Proceedings of the National Academy of Sciences 2014; 111: $15520-15525$.

18. Ziv E, Daley CL, Blower S. Potential public health impact of new tuberculosis vaccines. Emerging infectious diseases 2004; 10: 1529. 
19. Shirley DA, McArthur MA. The utility of human challenge studies in vaccine development: lessons learned from cholera. Vaccine (Auckl) 2011; 2011: 3-13.

20. Davids M, Pooran AS, Pietersen E, Wainwright HC, Binder A, Warren R, Dheda K. Regulatory T Cells Subvert Mycobacterial Containment in Patients Failing Extensively Drug-Resistant Tuberculosis Treatment. Am J Respir Crit Care Med 2018; 198: 104116.

21. Dheda K, Lenders L, Srivastava S, Magombedze G, Wainwright H, Raj P, Bush SJ, Pollara G, Steyn R, Davids M. Spatial Network Mapping of Pulmonary Multidrug-Resistant Tuberculosis Cavities Using RNA Sequencing. American journal of respiratory and critical care medicine 2019.

22. Holmes EC. BCG immunotherapy of lung cancer. Jpn J Surg 1980; 10: 1-6.

23. Babjuk M, Burger M, Zigeuner R, Shariat SF, van Rhijn BW, Comperat E, Sylvester RJ, Kaasinen E, Bohle A, Palou Redorta J, Roupret M, European Association of U. EAU guidelines on non-muscle-invasive urothelial carcinoma of the bladder: update 2013. Eur Urol 2013; 64: 639-653.

24. Rosenthal SR, McEnery JT, Raisys N. Aerogenic BCG vaccination against tuberculosis in animal and human subjects. Journal of Asthma Research 1968; 5: 309-323.

25. Yang H, Kruh-Garcia NA, Dobos KM. Purified protein derivatives of tuberculin--past, present, and future. FEMS Immunol Med Microbiol 2012; 66: 273-280.

26. Silver RF, Zukowski L, Kotake S, Li Q, Pozuelo F, Krywiak A, Larkin R. Recruitment of antigen-specific Th1-like responses to the human lung following bronchoscopic 
segmental challenge with purified protein derivative of Mycobacterium tuberculosis. American journal of respiratory cell and molecular biology 2003; 29: 117-123.

27. Walrath J, Zukowski L, Krywiak A, Silver RF. Resident Th1-like effector memory cells in pulmonary recall responses to Mycobacterium tuberculosis. Am J Respir Cell Mol Biol 2005; 33: 48-55.

28. Muranski P, Borman ZA, Kerkar SP, Klebanoff CA, Ji Y, Sanchez-Perez L, Sukumar M, Reger RN, Yu Z, Kern SJ, Roychoudhuri R, Ferreyra GA, Shen W, Durum SK, Feigenbaum L, Palmer DC, Antony PA, Chan CC, Laurence A, Danner RL, Gattinoni L, Restifo NP. Th17 cells are long lived and retain a stem cell-like molecular signature. Immunity 2011; 35: 972-985.

29. Schwander S, Dheda K. Human lung immunity against Mycobacterium tuberculosis: insights into pathogenesis and protection. Am J Respir Crit Care Med 2011; 183: 696707.

30. Dijkman K, Sombroek CC, Vervenne RAW, Hofman SO, Boot C, Remarque EJ, Kocken CHM, Ottenhoff THM, Kondova I, Khayum MA, Haanstra KG, Vierboom MPM, Verreck FAW. Prevention of tuberculosis infection and disease by local BCG in repeatedly exposed rhesus macaques. Nature Medicine 2019; 25: 255-262.

31. Satti I, Meyer J, Harris SA, Thomas Z-RM, Griffiths K, Antrobus RD, Rowland R, Ramon RL, Smith M, Sheehan S. Safety and immunogenicity of a candidate tuberculosis vaccine MVA85A delivered by aerosol in BCG-vaccinated healthy adults: a phase 1, doubleblind, randomised controlled trial. The Lancet Infectious diseases 2014; 14: 939-946. 
32. Aguirre-Blanco AM, Lukey PT, Cliff JM, Dockrell HM. Strain-dependent variation in Mycobacterium bovis BCG-induced human T-cell activation and gamma interferon production in vitro. Infect Immun 2007; 75: 3197-3201. 


\section{FIGURE LEGENDS}

Figure 1: (A) Overview of participant groups and study procedure. (B) Trial design. (C) The frequency and severity of unanticipated adverse events experienced by study participants undergoing bronchoscopy and lung challenge with purified-protein-derivative (PPD) and live Bacille-Calmette-Guerin (BCG). (D) Number of participants receiving PPD and BCG doses for instillation into the lungs and dose optimization.

Figure 2: (A) The frequency (\%) and (B) relative risk of anticipated adverse events in participants undergoing a single bronchoscopy (non-challenge; $\mathrm{n}=32$ ) and those undergoing lung challenge with purified-protein-derivative (PPD) and Bacille-Calmette-Guerin (BCG) (lung challenge; $n=74$ ). (C) The frequency and severity of unanticipated adverse events stratified by participant subgroup $(\mathrm{n}=106)$.

\section{Figure 3: The effect of bronchoscopy on lung immune responses in the saline control} segment. We performed a baseline bronchoscopy and saline instillation into different lung lobes (RUL - right upper lobe; RLL: right lower lobe; LLL- left lower lobe) followed by a second bronchoscopy after 3 days was performed in 4 healthy individuals. (A) Total cell counts were determined by microscopy. Biomarker expression was measured by flow cytometry for (B) perforin and granulysin expression on $\mathrm{CD}^{+} \mathrm{T}$-cells, (C) $\mathrm{CD} 4^{+} \mathrm{IFN}-\gamma$ expression and (D) $\mathrm{CD} 4^{+} \mathrm{CD} 69^{+}$expression.

\section{Figure 4: Optimisation of the Bacille-Calmette-Guerin (BCG) concentration} bronchoscopically instilled into the lungs using participants with a single previous episode of TB. Three concentrations of BCG at $10^{2}, 10^{3}$ and $10^{4}$ colony forming units (CFU) were chosen for instillation and broncho-alveolar lavage (BAL) fluid were collected from the challenged lung segments. Several indicators of lung-specific immunity were assessed at each concentration before (pre) and after BCG challenge (post). These included (A) Cell 
numbers counted by microscopy and expressed per ml of BAL fluid. (B) The frequency of the different BAL cell types including macrophages $\left(\mathrm{CD} 4^{+} \mathrm{CD} 68^{+}\right)$, dendritic cells $\left(\mathrm{CD} 83^{+} \mathrm{HLADR} / \mathrm{DQ} / \mathrm{DP}^{+}\right)$, natural killer cells $\left(\mathrm{CD}^{+} 6^{+}\right), \mathrm{T}$-cells $\left(\mathrm{CD}^{+}\right)$and neutrophils $\left(\mathrm{CD}_{6} \mathrm{~b}^{+} \mathrm{NGAL}^{+}\right)$, as measured by flow cytometry. (C-D) The concentration of Immunoglobulin-G (IgG) and IgA antibodies, respectively, secreted in BAL fluid and measured by ELISA. (E) The transcriptomic profile of BAL cells as measured by RNA sequencing and represented as a volcano plot of individual differentially expressed genes (DEGs). Each concentration is compared to baseline bronchoscopy and expressed as a Log2 fold change. Yellow dots indicate DEGs with FDR $<0.05$ (horizontal dashed lines) and the vertical dashed lines indicates Log2 fold change $\geq 1$. The number of DEGs meeting these criteria are indicated in each volcano plot and the p-value shown in the figure compares the different concentrations and was calculated using the G-test (F) Proteomic analysis of BAL supernatants as measured by mass spectrometry and represented as volcano plots showing the abundance of individual proteins. Permutation-based multiple testing correction was performed. BCG concentrations are compared to baseline bronchoscopy (B1) and proteins that survived the threshold of FDR $=0.05$ and $\mathrm{S}_{0}=0.1$ are highlighted in orange and are considered statistically significant. The number of dysregulated proteins (DP) meeting these criteria are indicated in each volcano plot and the p-value shown in the figure compares the different concentrations using the G-test. The number of participant samples (n) for each experiment are shown above the corresponding graphs. All experiments presented here were performed using samples from participants with a single previous episode of TB ("Previous TB” group). For (A-D), statistical analysis between pre- and post-challenge was performed using the Wilcoxon Rank sum test and a p-value $<0.05\left(^{*}\right)$ was considered statistically significant. 
Figure 5: Optimisation of the purified-protein-derivative (PPD) concentration bronchoscopically instilled into the lungs of participants with a single previous episode of TB. (A) was initially tested by intradermal administration of the two concentrations $[0.2$ tuberculin (TU) and $0.5 \mathrm{TU}$ ] into the skin of healthy volunteers, the size of the induration was measured three days later. Subsequently, PPD was bronchoscopically instilled into the lung at these concentrations to determine the effect on (B-C) the concentration of immunoglobulin-G (IgG) and IgA antibodies, respectively, secreted in BAL fluid and measured by ELISA (antibody concentration measurements were performed at a PPD concentration of $0.5 \mathrm{TU}$ only); (D) BAL cell numbers counted by microscopy and expressed per ml of BAL fluid; (E) The frequency of the different BAL cell types including macrophages $(\mathrm{CD} 4+\mathrm{CD} 68+)$, dendritic cells $(\mathrm{CD} 83+\mathrm{HLADR} / \mathrm{DQ} / \mathrm{DP}+)$, natural killer cells $(\mathrm{CD} 56+)$ and T-cells (CD3+), as measured by flow cytometry; and (F) intracellular cytokine expression by CD4 ${ }^{+}$T-cells including IFN- $\gamma(\mathrm{Th} 1)$ and CCR6 ${ }^{+} \mathrm{IL}-17^{+}$(Th17 homing cells), as measured by flow cytometry. All experiments presented here were performed using samples from participants with a single previous episode of TB (“Previous TB” group). Statistical analysis between pre- and post-challenge was performed using the Wilcoxon Rank sum test and a p-value $<0.05(*)$ was considered statistically significant.

Figure 6: Comparison of immune responses in different biological compartments and using different PPD stimulation strategies as measured by flow cytometry (Th1, Th2 and Th17) (A) Selected cytokine (Th1, Th2, Th17) responses were measured and compared in (A) broncho-alveolar lavage (BAL) versus peripheral blood cells retrieved prior to lung challenge (at baseline); (B) BAL cells retrieved from a baseline bronchoscopy, and stimulated with purified-protein-derivative (PPD) for 3 days in cell culture plates (in vitro) versus BAL cells retrieved from the PPD challenged lung segment after 3 days (in vivo). All experiments presented here were performed using samples from participants with a single 
previous episode of TB (“Previous TB” group). These data are presented as median and interquartile range. Statistical analysis was performed using the Wilcoxon Rank sum test and a p-value $<0.05(*)$ was considered statistically significant. 


\section{TABLES}

Table 1: Participant demographics and clinical parameters stratified by participant subgroups

\begin{tabular}{|c|c|c|c|c|c|c|}
\hline & $\begin{array}{c}\text { All } \\
(n=106)\end{array}$ & $\begin{array}{l}\text { Sterilizing } \\
\text { immunity } \\
(n=12)\end{array}$ & $\begin{array}{l}\text { Latently } \\
\text { infected } \\
(n=33)\end{array}$ & $\begin{array}{c}\text { Previous } \\
\text { TB } \\
(n=37)\end{array}$ & $\begin{array}{c}\text { Recurrent } \\
\text { TB } \\
(n=24)\end{array}$ & $\begin{array}{c}P- \\
\text { value }\end{array}$ \\
\hline $\begin{array}{l}\text { Gender: } \\
\text { Female: } \mathbf{n}(\%)\end{array}$ & $63(59)$ & $6(50)$ & $27(82)$ & $21(57)$ & $9(38)$ & 0.74 \\
\hline $\begin{array}{l}\text { Age (years): } \\
\text { median (\#IQR) }\end{array}$ & $28(23-37)$ & $26(23-39)$ & $31(25-38)$ & $27(23-35)$ & $28(23-41)$ & 0.78 \\
\hline $\begin{array}{l}\text { Non-smokers: } \\
\text { n (\%) }\end{array}$ & $106(100)$ & $12(100)$ & $33(100)$ & $37(100)$ & $24(100)$ & $\mathrm{n} / \mathrm{a}^{*}$ \\
\hline \begin{tabular}{|l} 
Race: $\mathbf{n}(\mathbf{\%})$ \\
Black African \\
Mixed ancestry
\end{tabular} & $\begin{array}{c}100(94) \\
6(6)\end{array}$ & $\begin{array}{c}10(83) \\
2(17)\end{array}$ & $\begin{array}{c}31(94) \\
2(6)\end{array}$ & $\begin{array}{l}37(100) \\
0(0)\end{array}$ & $\begin{array}{l}22(92) \\
2(8)\end{array}$ & 0.71 \\
\hline $\begin{array}{l}\text { HIV uninfected: } \\
\text { n (\%) }\end{array}$ & $106(100)$ & $12(100)$ & $33(100)$ & $37(100)$ & $24(100)$ & $\mathrm{n} / \mathrm{a}^{*}$ \\
\hline $\begin{array}{l}\text { BCG vaccinated at birth: } \\
\text { n (\%) }\end{array}$ & $106(100)$ & $12(100)$ & $33(100)$ & 37 (100) & $24(100)$ & $\mathrm{n} / \mathrm{a}^{*}$ \\
\hline 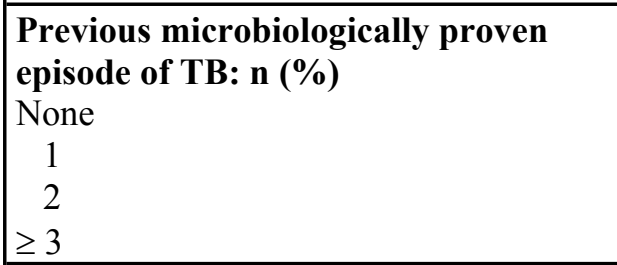 & $\begin{array}{l}- \\
- \\
-\end{array}$ & $\begin{array}{c}12(100) \\
0(0) \\
0(0) \\
0(0)\end{array}$ & $\begin{array}{c}33(100) \\
0(0) \\
0(0) \\
0(0)\end{array}$ & $\begin{array}{c}0(0) \\
37(100) \\
0(0) \\
0(0)\end{array}$ & $\begin{array}{c}0(0) \\
0(0) \\
23(96) \\
1(4)\end{array}$ & $\mathrm{n} / \mathrm{a}^{*}$ \\
\hline $\begin{array}{l}{ }^{\# \#} \text { QFT result: n (\%) } \\
\text { Positive: } \\
\text { Negative: }\end{array}$ & $\begin{array}{l}- \\
-\end{array}$ & $\begin{array}{c}0(0) \\
12(100)\end{array}$ & $\begin{array}{c}33(100) \\
0(0)\end{array}$ & $\begin{array}{c}35(95) \\
2(5)\end{array}$ & $\begin{array}{c}24(100) \\
0(0)\end{array}$ & $\begin{array}{l}<0.01 \\
<0.01\end{array}$ \\
\hline \begin{tabular}{|l|} 
Chest X-ray: n (\%) \\
Signs of previous TB \\
Scarring \\
Calcified granulomas \\
Volume loss \\
Old fibro-cavitary disease \\
Pleural thickening \\
\end{tabular} & $\begin{array}{l}50(47) \\
41(39) \\
42(40) \\
38(36) \\
26(25) \\
29(27)\end{array}$ & $\begin{array}{l}0(0) \\
0(0) \\
0(0) \\
0(0) \\
0(0) \\
0(0)\end{array}$ & $\begin{array}{l}0(0) \\
0(0) \\
0(0) \\
1(5) \\
0(0) \\
0(0)\end{array}$ & $\begin{array}{l}31(84) \\
26(70) \\
27(46) \\
20(54) \\
13(35) \\
13(35)\end{array}$ & $\begin{array}{l}19(79) \\
15(63) \\
15(63) \\
17(71) \\
13(54) \\
16(66)\end{array}$ & $\begin{array}{l}0.70^{* *} \\
0.08^{* *} \\
0.56^{* *} \\
0.76^{* *} \\
0.55^{* *} \\
0.76^{* *} \\
\end{array}$ \\
\hline $\begin{array}{l}\text { CHIM: } \mathbf{n}(\boldsymbol{\%}) \\
\text { No lung-challenge } \\
\text { PPD challenge } \\
\text { BCG challenge }\end{array}$ & $\begin{array}{l}32(30) \\
74(70) \\
74(70)\end{array}$ & $\begin{array}{c}1(8) \\
11(92) \\
11(92)\end{array}$ & $\begin{array}{l}4(12) \\
29(88) \\
29(88)\end{array}$ & $\begin{array}{l}12(32) \\
25(68) \\
25(68)\end{array}$ & $\begin{array}{l}15(62) \\
9(38) \\
9(38)\end{array}$ & 0.76 \\
\hline $\begin{array}{l}\text { Median BAL cell concentration }\left[\times 10^{5 /}\right. \\
\text { ml BAL fluid] ( }(\text { IQR; } \mathbf{n})\end{array}$ & & & & & & \\
\hline $\begin{array}{l}\text { Baseline Bronchoscopy } \\
\text { Saline only challenged segment }\end{array}$ & $\begin{array}{l}1.37 \\
(0.93-2.04 \\
106) \\
1.68\end{array}$ & $\begin{array}{c}1.24 \\
(0.75-1.43 ; 12) \\
1.01 \\
(0.61-1.63 ; 10)\end{array}$ & $\begin{array}{c}1.26 \\
(0.91-1.52 \\
32) \\
1.84\end{array}$ & $\begin{array}{c}1.65 \\
(1.09-2.90 \\
36) \\
1.74\end{array}$ & $\begin{array}{c}1.45 \\
(0.92- \\
3.63 ; 27) \\
1.75\end{array}$ & $\begin{array}{l}0.051 \\
0.257\end{array}$ \\
\hline
\end{tabular}




\begin{tabular}{|l|c|c|c|c|c|c|} 
& $(1.06-2.30 ;$ & & $(1.20-2.27 ;$ & $(0.94-2.61 ;$ & $(0.95-$ & \\
& $67)$ & & $28)$ & $19)$ & $2.65 ; 10)$ & \\
PPD (0.5 ${ }^{\# \#}$ TU) challenged segment & 5.46 & 1.24 & 4.11 & 8.82 & 9.08 & $\mathbf{0 . 0 1 0}$ \\
& $(2.16-11.80 ;$ & $(0.70-3.11 ; 11)$ & $(1.79-10.60 ;$ & $(5.55-15.40 ;$ & $(2.82-$ & \\
BCG (10 \#\#\# CFU) challenged segment & $66)$ & & $28)$ & $18)$ & $28.50 ; 9)$ & \\
& 2.21 & 1.24 & 1.74 & 3.04 & 2.50 & $\mathbf{0 . 0 0 3}$ \\
& $(1.38-3.65 ;$ & $(0.78-2.42 ; 11)$ & $(1.27-3.10 ;$ & $(2.07-4.70 ;$ & $(1.86-$ & \\
& $66)$ & & $25)$ & $20)$ & $6.60 ; 10)$ & \\
\hline
\end{tabular}

*p-values were not calculated as these parameters composed the basis of our TB susceptibility grouping.

** $\mathrm{p}$ - value here was calculated based on the comparison between previous TB and recurrent TB groups.

"interquartile range

\#QuantiFERON release assay

\#\# tuberculin units

\#\#\#" colony forming units 
Table 2: Details of each unanticipated adverse event that occurred during the study period

\begin{tabular}{|c|c|c|c|c|c|c|c|}
\hline $\begin{array}{l}\text { Participant } \\
\text { ID }\end{array}$ & $\begin{array}{l}\text { Participant } \\
\text { Group }\end{array}$ & $\begin{array}{l}\text { Lung } \\
\text { challenge }\end{array}$ & $\begin{array}{l}\text { Adverse event } \\
\text { description }\end{array}$ & $\begin{array}{c}\text { Grading of } \\
\text { adverse event }\end{array}$ & $\begin{array}{l}\text { Causal relationship } \\
\text { of adverse event }\end{array}$ & $\begin{array}{l}\text { Time to } \\
\text { symptom } \\
\text { resolution }\end{array}$ & $\begin{array}{c}\text { Description of intervention and clinical } \\
\text { status of participant at the end of } \\
\text { study period. }\end{array}$ \\
\hline T090 & $\begin{array}{l}\text { Sterilizing } \\
\text { Immunity }\end{array}$ & Yes & $\begin{array}{l}\text { Likely herpes } \\
\text { simplex } \\
\text { reactivation on } \\
\text { lips }\end{array}$ & Moderate & $\begin{array}{l}\text { Possible link to the } \\
\text { bronchoscopy } \\
\text { procedure }\end{array}$ & 7 days & $\begin{array}{l}\text { Participant given an anti-viral (acylovir). } \\
\text { All symptoms completely resolved }\end{array}$ \\
\hline T134 & $\begin{array}{l}\text { Sterilizing } \\
\text { Immunity }\end{array}$ & Yes & $\begin{array}{l}\text { Passenger in a } \\
\text { motor vehicle } \\
\text { accident }\end{array}$ & Mild & $\begin{array}{l}\text { Unlikely to be } \\
\text { related to the } \\
\text { procedure }\end{array}$ & 1 day & No intervention. \\
\hline T037 & LTBI & No & $\begin{array}{c}\text { Superficial } \\
\text { pressure abrasion } \\
\text { on lips }\end{array}$ & Moderate & $\begin{array}{l}\text { Definite link to the } \\
\text { bronchoscopy } \\
\text { procedure }\end{array}$ & 7 days & $\begin{array}{l}\text { Participant given an anti-histamine } \\
\text { (cetirizine } 10 \mathrm{mg} \text { daily). } \\
\text { All symptoms completely resolved. }\end{array}$ \\
\hline T007 & $\begin{array}{l}\text { Previous } \\
\text { TB }\end{array}$ & Yes & Acute bronchitis & Mild & $\begin{array}{l}\text { Possible link to the } \\
\text { intervention (lung } \\
\text { challenge) }\end{array}$ & 7 days & $\begin{array}{l}\text { Participant given antibiotics, salbutamol } \\
\text { and omeprazole. } \\
\text { All symptoms completely resolved. }\end{array}$ \\
\hline T011 & $\begin{array}{l}\text { Previous } \\
\text { TB }\end{array}$ & Yes & Pyrexia & Mild & $\begin{array}{l}\text { Possible link to the } \\
\text { intervention (lung } \\
\text { challenge) }\end{array}$ & 1 day & $\begin{array}{l}\text { Participant admitted to hospital and given } \\
\text { paracetamol; symptoms resolved during } \\
\text { the evening. All symptoms completely } \\
\text { resolved by the next day. }\end{array}$ \\
\hline T026 & $\begin{array}{l}\text { Previous } \\
\text { TB }\end{array}$ & No & Epigastric pain & Moderate & $\begin{array}{l}\text { Possible link to the } \\
\text { bronchoscopy } \\
\text { procedure. }\end{array}$ & 4 hours & $\begin{array}{l}\text { Participant given antacids. } \\
\text { All symptoms completely resolved. }\end{array}$ \\
\hline T030 & $\begin{array}{l}\text { Previous } \\
\text { TB }\end{array}$ & No & Acute tonsillitis & Moderate & $\begin{array}{l}\text { Unlikely to be } \\
\text { related to the } \\
\text { procedure. }\end{array}$ & 5 days & $\begin{array}{l}\text { Participant given 5-day cause of oral } \\
\text { antibiotics (amoxicillin + clavulanic } \\
\text { acid). All symptoms completely resolved. }\end{array}$ \\
\hline T048 & $\begin{array}{l}\text { Previous } \\
\text { TB }\end{array}$ & Yes & Tachycardia & Mild & $\begin{array}{l}\text { Possible link to the } \\
\text { bronchoscopy } \\
\text { procedure. }\end{array}$ & 1 day & $\begin{array}{l}\text { Patient started on amlodipine and } \\
\text { referred to primary health facility for } \\
\text { long term management. }\end{array}$ \\
\hline T124 & $\begin{array}{l}\text { Previous } \\
\text { TB }\end{array}$ & Yes & Acute tonsillitis & Moderate & $\begin{array}{l}\text { Unlikely to be } \\
\text { related to the } \\
\text { procedure. }\end{array}$ & 7 days & $\begin{array}{l}\text { Participant given oral antibiotics } \\
\text { (amoxycillin). } \\
\text { All symptoms completely resolved. }\end{array}$ \\
\hline T074 & $\begin{array}{l}\text { Recurrent } \\
\text { TB }\end{array}$ & Yes & Hypertension & Mild & $\begin{array}{l}\text { Possible link to the } \\
\text { bronchoscopy } \\
\text { procedure. }\end{array}$ & $\begin{array}{l}\text { Likely pre- } \\
\text { existing } \\
\text { chronic } \\
\text { condition }\end{array}$ & $\begin{array}{l}\text { Patient blood pressure was well } \\
\text { controlled. Patient referred primary } \\
\text { health facility for further continued } \\
\text { monitoring. }\end{array}$ \\
\hline
\end{tabular}




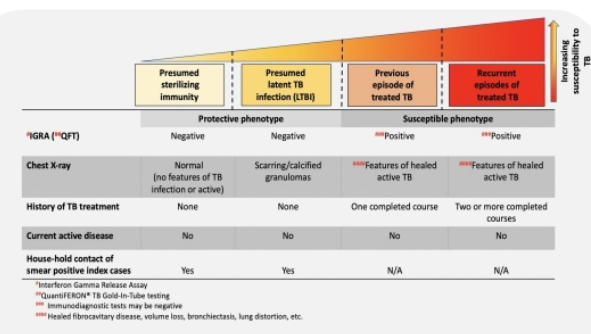

C
$B_{\text {oor }}$

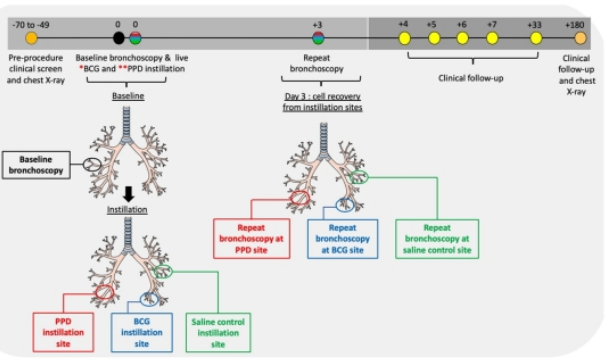

D

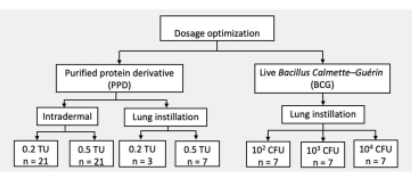

Figure 1: (A) Overview of participant groups and study procedure. (B) Trial design. (C) The frequency and severity of unanticipated adverse events experienced by study participants undergoing bronchoscopy and lung challenge with purified-protein-derivative (PPD) and live Bacille-Calmette-Guerin (BCG). (D) Number of participants receiving PPD and BCG doses for instillation into the lungs and dose optimization.

$1053 \times 595 \mathrm{~mm}(96 \times 96 \mathrm{DPI})$ 

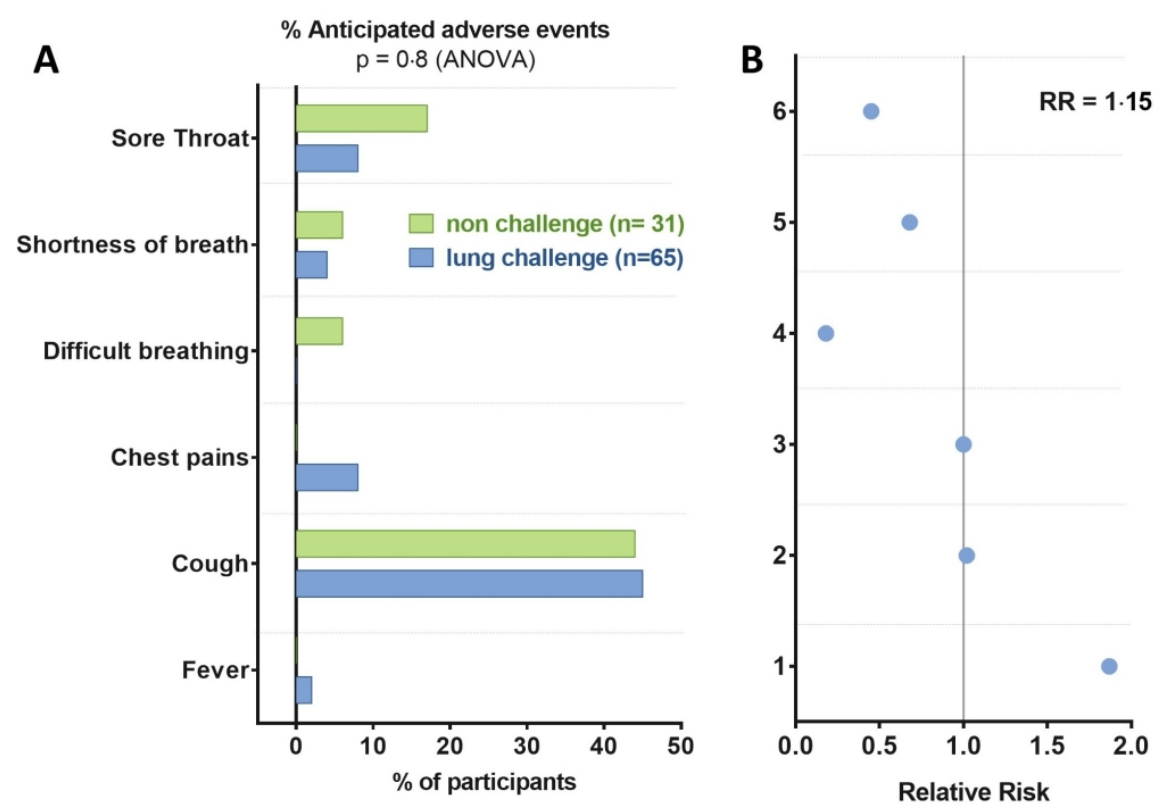

C

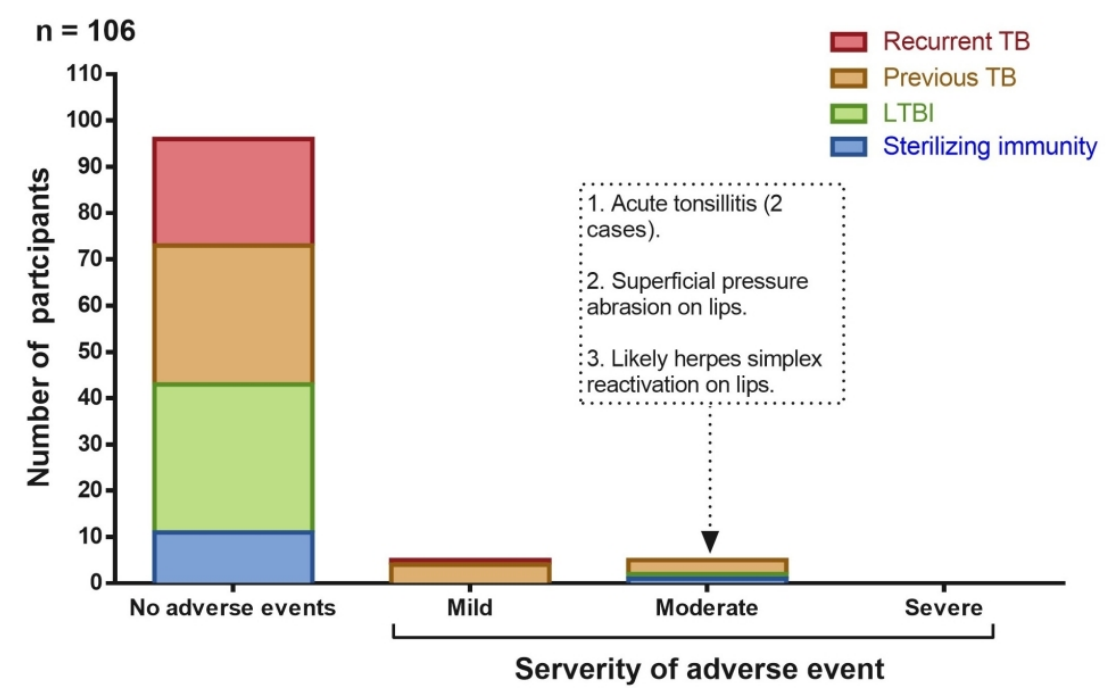

Figure 2: (A) The frequency (\%) and (B) relative risk of anticipated adverse events in participants undergoing a single bronchoscopy (non-challenge; $n=32$ ) and those undergoing lung challenge with purifiedprotein-derivative (PPD) and Bacille-Calmette-Guerin (BCG) (lung challenge; $n=74$ ). (C) The frequency and severity of unanticipated adverse events stratified by participant subgroup $(n=106)$.

$$
562 \times 711 \mathrm{~mm}(96 \times 96 \text { DPI) }
$$




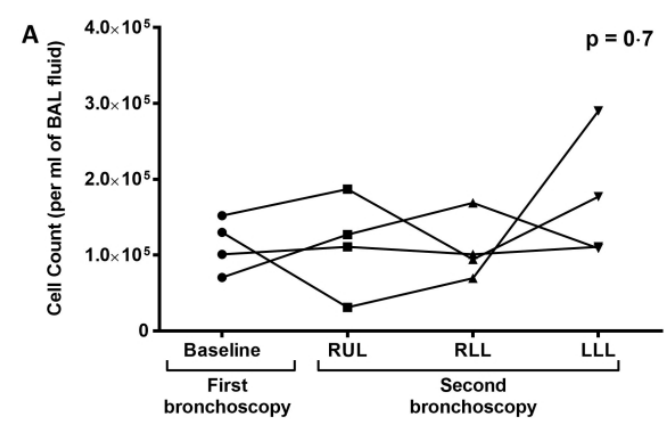

C

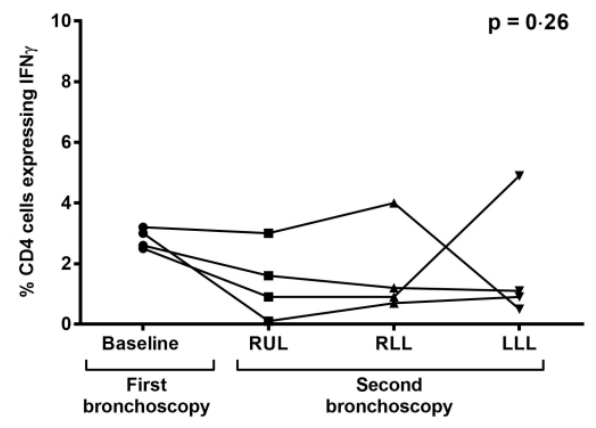

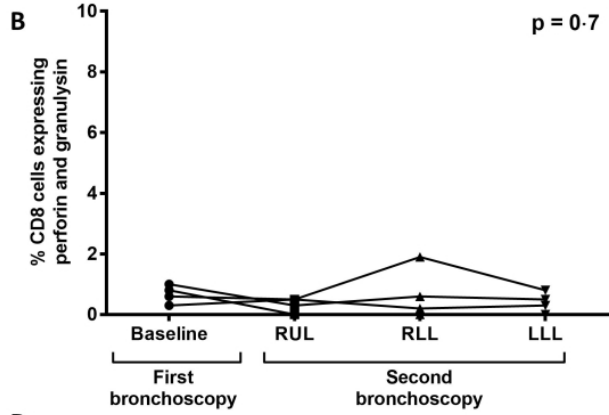

D

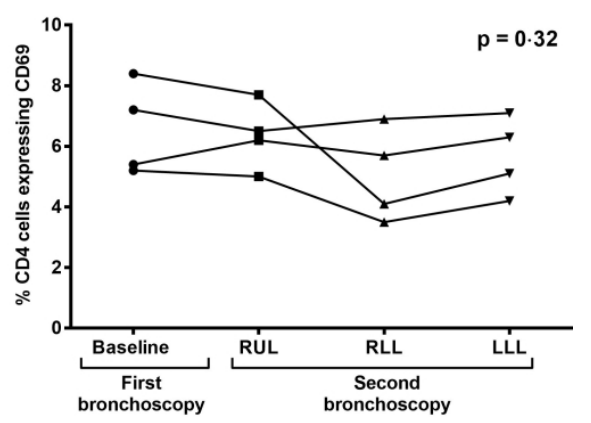

Figure 3: The effect of bronchoscopy on lung immune responses in the saline control segment. We performed a baseline bronchoscopy and saline instillation into different lung lobes (RUL - right upper lobe; RLL: right lower lobe; LLL- left lower lobe) followed by a second bronchoscopy after 3 days was performed in 4 healthy individuals. (A) Total cell counts were determined by microscopy. Biomarker expression was measured by flow cytometry for (B) perforin and granulysin expression on CD8+ T-cells, (C) CD4+IFN-Y expression and (D) CD4+CD69+ expression.

916×590mm (96 x 96 DPI) 


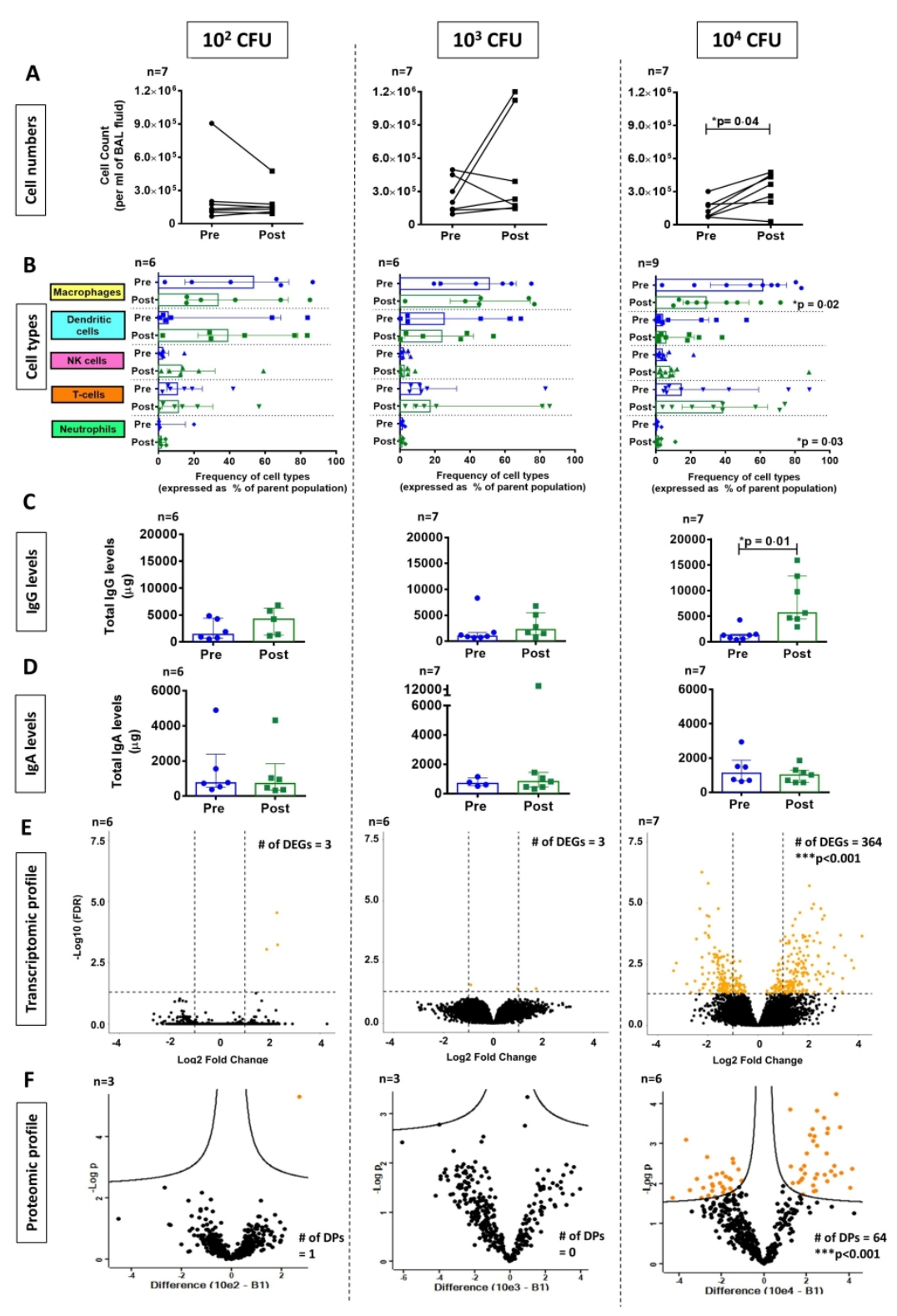

Figure 4: Optimisation of the Bacille-Calmette-Guerin (BCG) concentration bronchoscopically instilled into the lungs using participants with a single previous episode of TB. Three concentrations of BCG at 102,103 and 104 colony forming units (CFU) were chosen for instillation and broncho-alveolar lavage (BAL) fluid were collected from the challenged lung segments. Several indicators of lung-specific immunity were assessed at each concentration before (pre) and after BCG challenge (post). These included ( $A$ ) Cell numbers counted by microscopy and expressed per $\mathrm{ml}$ of BAL fluid. (B) The frequency of the different BAL cell types including macrophages (CD4+CD68+), dendritic cells (CD83+HLADR/DQ/DP+), natural killer cells (CD56+), T-cells

$(\mathrm{CD} 3+)$ and neutrophils (CD66b+NGAL+), as measured by flow cytometry. (C-D) The concentration of Immunoglobulin-G (IgG) and IgA antibodies, respectively, secreted in BAL fluid and measured by ELISA. (E) The transcriptomic profile of BAL cells as measured by RNA sequencing and represented as a volcano plot of individual differentially expressed genes (DEGs). Each concentration is compared to baseline bronchoscopy and expressed as a Log2 fold change. Yellow dots indicate DEGs with FDR < 0.05 (horizontal dashed lines) and the vertical dashed lines indicates Log2 fold change $\square 1$. The number of DEGs meeting these criteria are indicated in each volcano plot and the $\mathrm{p}$-value shown in the figure compares the different concentrations and 
was calculated using the G-test (F) Proteomic analysis of BAL supernatants as measured by mass spectrometry and represented as volcano plots showing the abundance of individual proteins. Permutationbased multiple testing correction was performed. BCG concentrations are compared to baseline bronchoscopy (B1) and proteins that survived the threshold of FDR $=0.05$ and S0 $=0.1$ are highlighted in orange and are considered statistically significant. The number of dysregulated proteins (DP) meeting these criteria are indicated in each volcano plot and the $p$-value shown in the figure compares the different concentrations using the G-test. The number of participant samples $(n)$ for each experiment are shown above the corresponding graphs. All experiments presented here were performed using samples from participants with a single previous episode of TB ("Previous TB" group). For (A-D), statistical analysis between pre- and post-challenge was performed using the Wilcoxon Rank sum test and a $p$-value $<0.05(*)$ was considered statistically significant.

$231 \times 338 \mathrm{~mm}(300 \times 300 \mathrm{DPI})$ 

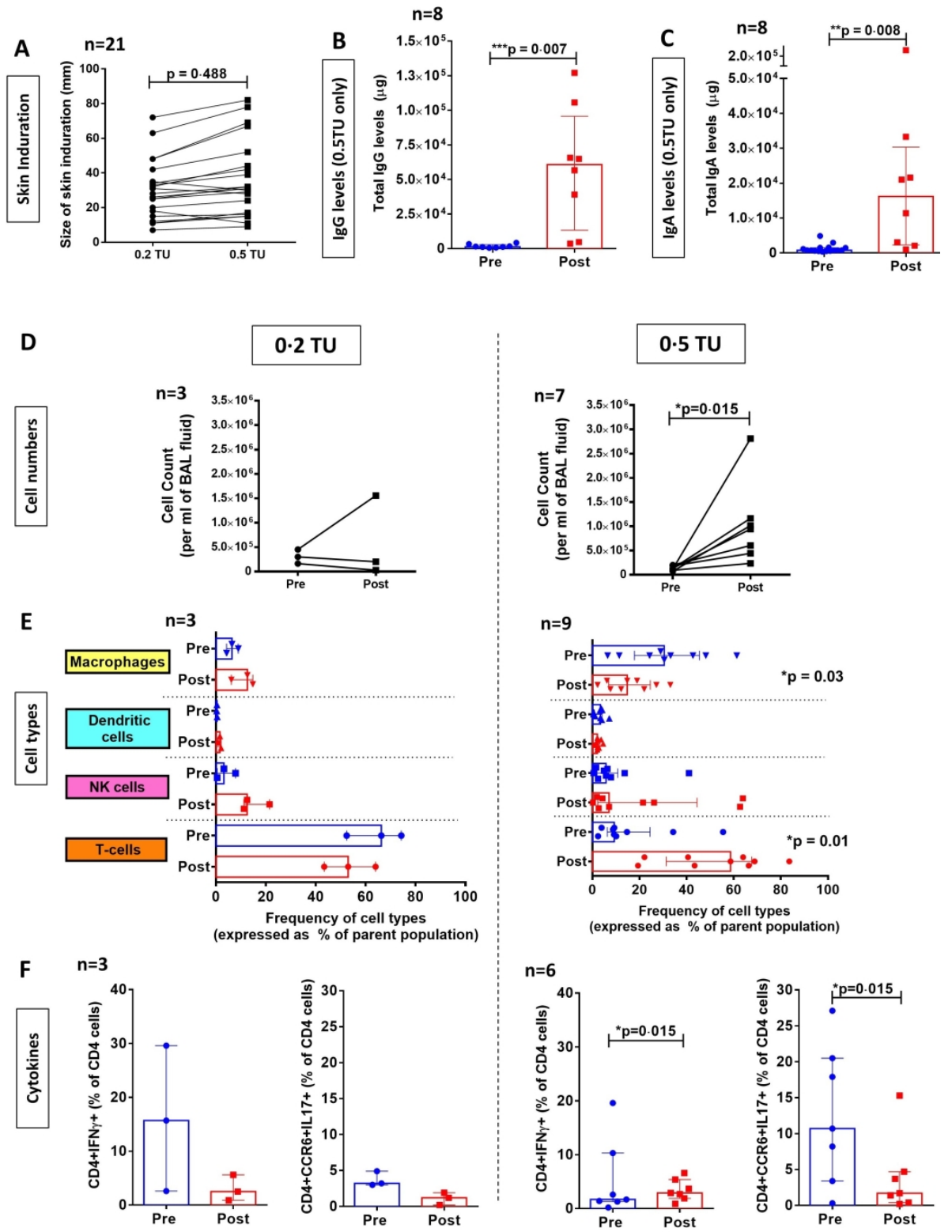

$n=9$
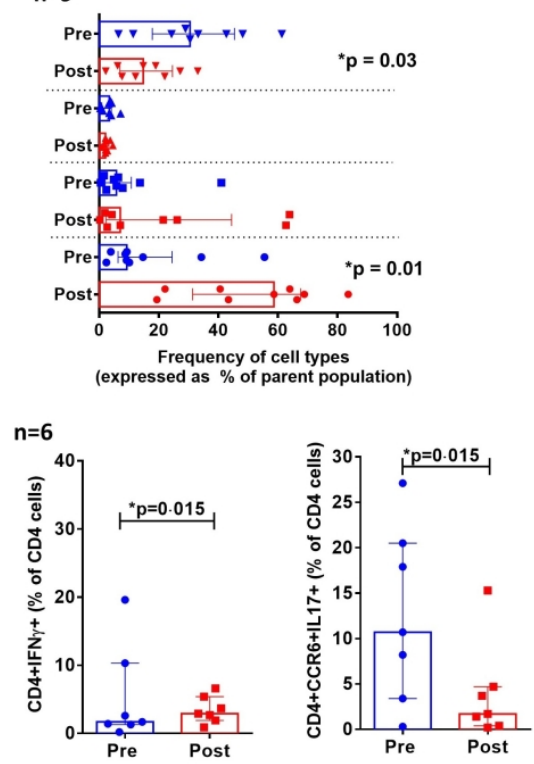

Figure 5: Optimisation of the purified-protein-derivative (PPD) concentration bronchoscopically instilled into the lungs of participants with a single previous episode of TB. (A) was initially tested by intradermal administration of the two concentrations [0.2 tuberculin (TU) and 0.5 TU] into the skin of healthy

volunteers, the size of the induration was measured three days later. Subsequently, PPD was bronchoscopically instilled into the lung at these concentrations to determine the effect on (B-C) the concentration of immunoglobulin-G (IgG) and IgA antibodies, respectively, secreted in BAL fluid and measured by ELISA (antibody concentration measurements were performed at a PPD concentration of 0.5 TU only); (D) BAL cell numbers counted by microscopy and expressed per $\mathrm{ml}$ of BAL fluid; (E) The frequency of the different BAL cell types including macrophages (CD4+CD68+), dendritic cells

(CD83+HLADR/DQ/DP+), natural killer cells (CD56+) and T-cells (CD3+), as measured by flow cytometry; and $(F)$ intracellular cytokine expression by CD4+ T-cells including IFN-Y (Th1) and CCR6+IL-17+ (Th17

homing cells), as measured by flow cytometry. All experiments presented here were performed using samples from participants with a single previous episode of TB ("Previous TB" group). Statistical analysis between pre- and post-challenge was performed using the Wilcoxon Rank sum test and a p-value $<0.05\left(^{*}\right)$ 
was considered statistically significant.

$708 \times 931 \mathrm{~mm}(96 \times 96 \mathrm{DPI})$ 


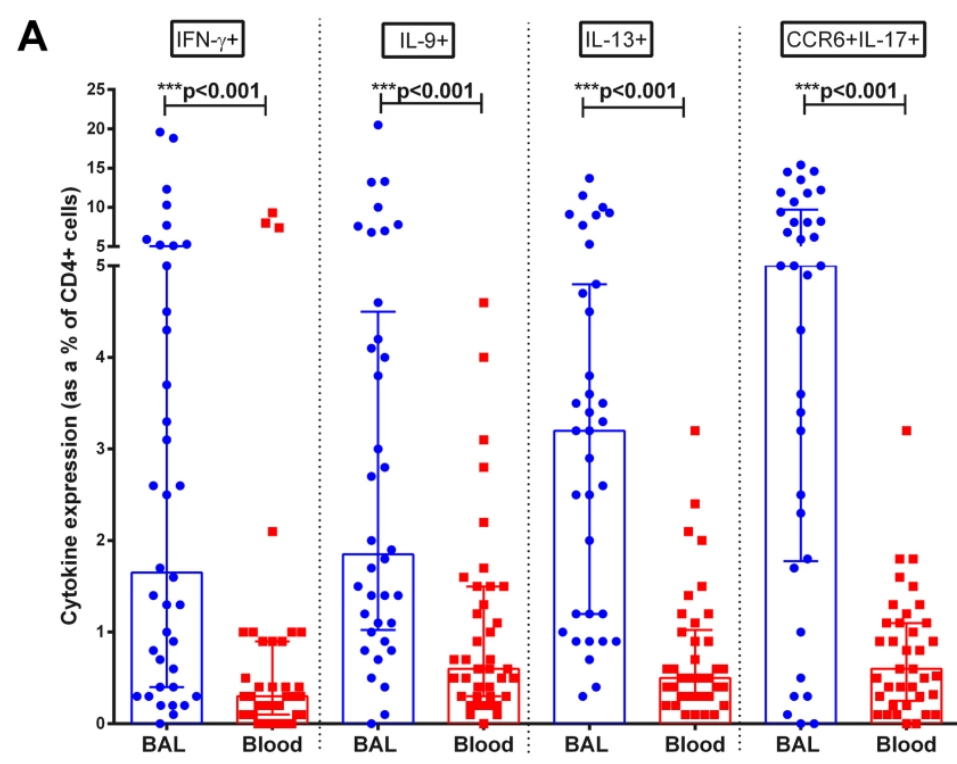

\section{B}

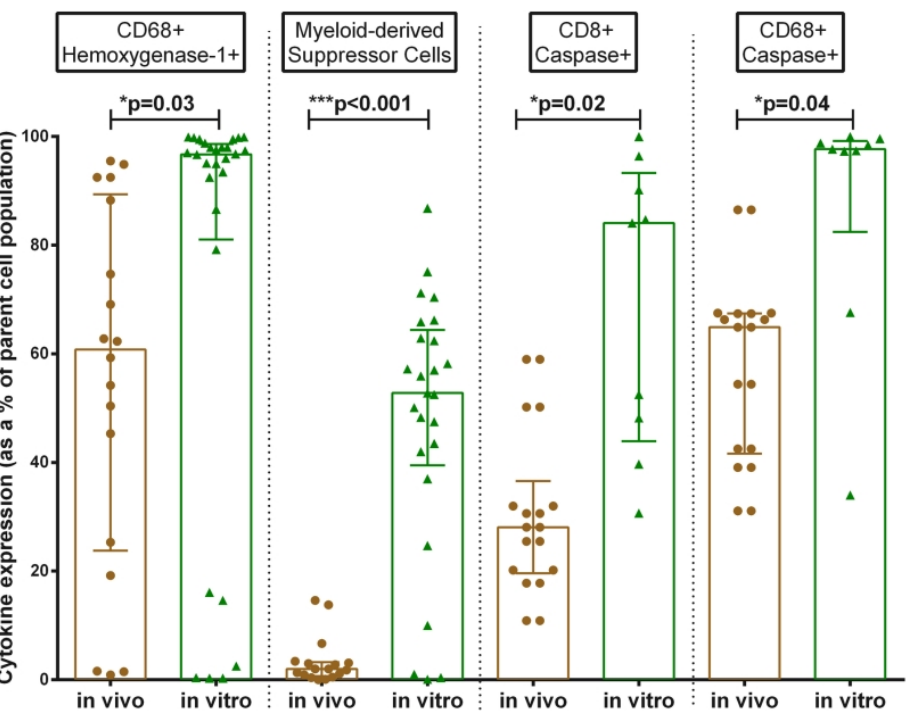

Figure 6: Comparison of immune responses in different biological compartments and using different PPD stimulation strategies as measured by flow cytometry (Th1, Th2 and Th17) (A) Selected cytokine (Th1, Th2, Th17) responses were measured and compared in (A) broncho-alveolar lavage (BAL) versus peripheral blood cells retrieved prior to lung challenge (at baseline); (B) BAL cells retrieved from a baseline bronchoscopy, and stimulated with purified-protein-derivative (PPD) for 3 days in cell culture plates (in vitro) versus BAL cells retrieved from the PPD challenged lung segment after 3 days (in vivo). All experiments presented here were performed using samples from participants with a single previous episode of TB ("Previous TB" group). These data are presented as median and interquartile range. Statistical analysis was performed using the Wilcoxon Rank sum test and a p-value $<0.05(*)$ was considered statistically significant.

$175 \times 260 \mathrm{~mm}(300 \times 300 \mathrm{DPI})$ 


\section{ONLINE SUPPLEMENT:}

\section{A Human Lung Challenge Model to Evaluate the Safety and Immunogenicity of PPD and Live BCG}

*Malika Davids ${ }^{1}$, *Anil Pooran ${ }^{1}$, Clemens Hermann ${ }^{2}$, Lynelle Mottay ${ }^{1}$, Fawziyah Thompson ${ }^{1}$, Jacob Cardenas $^{3}$, Jinghua Gu${ }^{3}$, Thearith Koeuth ${ }^{3}$, Richard Meldau ${ }^{1}$, Jason Limberis ${ }^{1}$, Phindile Gina ${ }^{1}$, Shashikant Srivastava ${ }^{3}$, Bridget Calder $^{2}$, Aliasgar Esmail ${ }^{1}$, Michele Tomasicchio ${ }^{1}$, Jonathan Blackburn², Tawanda Gumbo ${ }^{3}$, and Keertan Dheda ${ }^{1,4}$.

*Authors contributed equally; joint first authors

${ }^{1}$ Centre for Lung Infection and Immunity, Division of Pulmonology, Department of Medicine and UCT Lung Institute \& South African MRC/UCT Centre for the Study of Antimicrobial Resistance, University of Cape Town, Cape Town, South Africa.

${ }^{2}$ Department of Integrative Biomedical Sciences, Institute of Infectious Disease \& Molecular Medicine, Faculty of Health Sciences, University of Cape Town, Anzio Road Observatory, Cape Town 7925, South Africa.

${ }^{3}$ Baylor Institute for Immunology Research, 53620, Dallas, Texas, United States.

${ }^{4}$ Faculty of Infectious and Tropical Diseases, Department of Immunology and Infection, London School of Hygiene and Tropical Medicine, London, UK.

\section{Corresponding author:}

Keertan Dheda

Keertan.dheda@uct.ac.za

Division of Pulmonology \& UCT Lung Institute, Department of Medicine

Old Main Building, Observatory 7439, Cape Town, South Africa 


\section{METHODS}

\subsection{Preparation of BCG}

Bacille-Calmette-Guerin (BCG) culture SSI (Statum Serum Institute, Copenhagen, Denmark) was sourced for lung challenge experiments. Each tube comprised of a semi-dry mass of $\sim 2.5 \times 10^{8}$ colony-forming-units (CFU) of Mycobacterium Bovis BCG (Danish strain 1331). The contents were reconstituted in $1 \mathrm{ml}$ of sterile $0.9 \%$ saline and serial dilutions were subsequently made to obtain concentrations of $1 \times 10^{3}, 1 \times 10^{4}$ and $1 \times 10^{5}$ $\mathrm{CFU} / \mathrm{ml}$ for dose optimization studies. $100 \mu \mathrm{l}$ of each dilution was mixed into $15 \mathrm{ml}$ of sterile saline and instilled into the lung via bronchoscopy (giving a final CFU count of $1 \times 10^{2}$, $1 \times 10^{3}$ and $1 \times 10^{4}$, respectively). All dilutions were plated on $7 \mathrm{H} 9$ agar plates to confirm the CFU count at each dilution and bacterial viability.

\subsection{Preparation of purified protein derivative (PPD)}

Tuberculin PPD RT/23 (Statum Serum Institute, Copenhagen, Denmark) was sourced for skin testing and lung challenge experiments. Skin challenge was initially performed for PPD dose finding investigations. 100ul of Tuberculin PPD RT/23 at 5 Tuberculin units (TU)/ml and $2 \mathrm{TU} / \mathrm{ml}$ (equating to a final concentration of 0.5 and $0.2 \mathrm{TU}$, respectively) were simultaneously administered intradermally into the left and right forearms, respectively, of healthy individuals. The size of the induration was measured after 3 days. For lung challenge experiments, $100 \mu 1$ of 5TU and 2TU PPD (equating to a final concentration of 0.5 and $0.2 \mathrm{TU}$, respectively) was mixed in $15 \mathrm{ml}$ of sterile $0.9 \%$ saline and subsequently instilled into the lung via bronchoscopy (see below). 
Both PPD and BCG dilutions were prepared from GMP-grade pharmaceutical stocks in a Class II bio-safety cabinet under sterile conditions. As such, no testing for lipopolysaccharides or other contaminants was performed.

\subsection{Bronchoscopy procedure}

All bronchoscopies were performed by the study pulmonologist at the E-16 Respiratory Clinic at Groote Schuur Hospital, Cape Town. Study participants remained starved for at least 12 hours before and at least 2 hours after the procedure to minimize the risk of aspiration. Also prior to the procedure, a blood sample was collected and participants underwent a physical examination and were questioned regarding symptoms of cough, sputum production, dyspnea or chest pain. At the start of the bronchoscopy, participants were placed under general anaesthesia using a combination of fentanyl, midazolam and propofol (administered by a qualified anaesthetist). A laryngeal mask (LMA) was used to protect the airway. $2 \%$ lidocaine was topically applied to the nasal passage and throat followed by intubation and insertion of a fibreoptic flexible bronchoscope into the airways.

\subsection{Post-bronchoscopy procedure recovery and follow up}

Upon completion of the procedure (baseline and repeat bronchoscopies), participants were allowed to recover under close observation by the research nurse and anesthetist. Each participant was intensively followed up post-procedure (either telephonically or by home visit) by the research nurse daily for the first week, twice a week for the next month and weekly for the final two months (a total of three months). The frequency and description of any adverse events were recorded by the research nurse. Given the novelty of PPD and BCG lung challenge, especially in individuals from endemic countries with high $M$. $t b$ exposure, the first five recruited participants were hospitalized post-procedure for intensive clinical monitoring. 


\subsection{Bronchoalveolar lavage processing for proteomic analysis}

Cell-free bronchoalveolar lavage fluid (BALF) was stored in $15 \mathrm{ml}$ aliquots at $-80^{\circ} \mathrm{C}$ until further use. Each aliquot was thawed, debris removed by centrifugation at $3000 \mathrm{x}$ g for 10 minutes and the resulting supernatant filtered through a $0.20 \mu \mathrm{m}$ filter. The BALF was further concentrated to a volume of 1-2 ml using an Amicon Ultra-4ml Centrifugal Filter Unit (Sigma) with a $3 \mathrm{kDa}$ molecular weight cut-off. Filters were prewashed PBS $\mathrm{pH} 7.4$ prior to use. Protein concentration was estimated using a BCA protein quantitation kit (Thermo).

\subsection{Immuno-depletion and sample preparation for proteomic analysis}

One hundred $\mu \mathrm{g}$ of protein per patient was diluted in Buffer A (Agilent) and immunodepleted using a MARS HU-6 column (Agilent) according to manufacturers' instructions. The column was washed twice with Buffer A and the resulting fractions combined. The bound highabundance proteins were eluted using Buffer B (Agilent). Unbound fractions were buffer exchanged into denaturation buffer (6 M urea, $2 \mathrm{M}$ thiourea, $10 \mathrm{mM}$ Tris $\mathrm{pH} 8.0)$ and concentrated to a volume of 100-200 $\mu 1$ using an Amicon Ultra-0.5ml Centrifugal Filter Unit (Sigma) with a $3 \mathrm{kDa}$ molecular weight cut-off. Proteins were reduced with dithiothreitol at a final concentration of $1 \mathrm{mM}$ for 1 hour at room temperature. Free cysteine residues were alkylated by incubation in $5.5 \mathrm{mM}$ iodoacetamide for 1 hour at room temperature in the dark. Samples were diluted with 4 volumes of $20 \mathrm{mM}$ ammonium bicarbonate buffer $\mathrm{pH} 8.0$ with $20 \mathrm{mM} \mathrm{CaCl}_{2}$ and proteins digested with 2 ug of sequence-grade trypsin (NEB) at room temperature for $18 \mathrm{hrs}$. Digestion was stopped by addition of $0.1 \%$ formic acid (Sigma). Tryptic peptides were desalted using homemade STAGE tips containing Empore Octadecyl C18 solid-phase extraction disks (Supelco). C18 disks were activated with three washes with solvent B ( $80 \%$ acetonitrile, $0.1 \%$ formic acid) and equilibrated with three washes with solvent A ( $2 \%$ acetonitrile, $0.1 \%$ formic acid). Approximately $10 \mu \mathrm{g}$ of tryptic peptides were 
loaded onto the $\mathrm{C} 18$ disc, centrifuged at $4000 \times \mathrm{g}$ for 1 minute and washed three times with solvent A. Peptides were then eluted three times with solvent C ( $60 \%$ acetonitrile, $0.1 \%$ formic acid) into glass capillary tubes. Eluted peptides were dried in a vacuum and resuspended with solvent $\mathrm{A}$ ( $2 \%$ acetonitrile, $0.1 \%$ formic acid) at a concentration of about $200 \mathrm{ng} / \mu \mathrm{l}$ prior to measurement. A pool of all samples was created for quality assurance during measurements.

\subsection{LC-MS/MS analysis}

Separation of peptides by liquid chromatography was performed using a homemade $100 \mu \mathrm{m}$ ID $\times 20 \mathrm{~mm}$ precolumn packed with $\mathrm{C} 18$ Luna beads $(5 \mu \mathrm{m}$ diameter, $100 \AA$ pore size; Phenomenex $04 \mathrm{~A}-5452$ ) connected to a $75 \mu \mathrm{m} \times 200 \mathrm{~mm}$ analytical column packed with Aeris peptide C18 beads (3.6 um diameter; Phenomenex 00B-4507-AN) connected to an Ultimate 3500 RS nano UPLC system (Dionex). Desalted peptides were loaded onto the column with a starting mobile phase of $2 \% \mathrm{ACN}, 0.1 \%$ formic acid and separated at a constant flow rate at $400 \mathrm{~nL} /$ minute by the following gradient: 10 minute at $2 \% \mathrm{ACN}$, increase to $6 \% \mathrm{ACN}$ for 2 minute, to $30 \% \mathrm{ACN}$ over 120 minute, to $80 \% \mathrm{ACN}$ over 5 minute, followed by a column wash of $80 \%$ for 13 minute. Mass spectra were collected on a Q Exactive mass spectrometer (Thermo) in a data-dependent manner with automatic switching between MS and MS/MS scans using a top-10 method. Peptides were ionised by electrospray ionisation and MS spectra were acquired at a resolution of 70,000 with a target value of $3 \times 10^{6}$ ions or a maximum integration time of $250 \mathrm{~ms}$. The scan range was restricted between 300 and $1750 \mathrm{~m} / \mathrm{z}$. Peptide fragmentation was performed by higher-energy collision dissociation (HCD) with the energy set at $25 \mathrm{NCE}$. Intensity threshold for ions selection was fixed at $1.7 \times 10^{4}$ with charge exclusion of $z=1$ and $z>5$. The MS/MS spectra were acquired 
at a resolution of 17,500 , with a target value of $2 \times 10^{5}$ ions or a maximum integration time of $120 \mathrm{~ms}$ and the isolation window was set at $4.0 \mathrm{~m} / \mathrm{z}$.

\section{8 $\underline{\text { Proteomic data analysis }}$}

RAW data files were processed with MaxQuant version 1.5.4.1 for protein and peptide identification using the Andromeda search engine and the Uniprot proteomes for Homo sapiens (Proteome ID: UP000005640, 71785 proteins, 07/02/2018), M. bovis BCG Pasteur (Proteome ID: UP000001472, 3891 proteins, 03/09/2018) and M. tuberculosis H37Rv (Proteome ID: UP000001584, 3993 proteins, 03/01/2018). Default parameter settings were used for the MS/MS database search, with carbamidomethylation of cysteine residues and acetylation of the protein $\mathrm{N}$-terminus selected as fixed modifications.

Trypsin/P was selected as protease, label-free quantitation (LFQ) and the "match between runs" feature were enabled. Reverse hits and common contaminants were removed from the data sets and only protein identifications with a q-value $<0.01$ were considered for the further analysis. Data analysis was performed in Perseus version 1.6.2.3. For each comparison, LFQ values were $\log 2(\mathrm{x})$ transformed. Dysregulated proteins were identified by volcano plot analysis using permutation-based multiple testing correction. Values for determining significantly dysregulated proteins were kept at the default settings of FDR $=0.05$ and background variability $\mathrm{S}_{0}=0.1$.

\subsection{Transcriptomic analysis}

1.9.1 Bioinformatics analysis: Quality assessment on raw sequencing reads was performed using FastQC ${ }^{1}$. The adapters were trimmed and low-quality reads $(<20)$ were filtered using cutadapt ${ }^{2}$. Reads were aligned to the human reference genome $(\mathrm{GRCh} 38)^{3}$ using hisat $2^{4}$. 
Aligned SAM files were converted to BAM format using samtools ${ }^{5}$ and feature Counts ${ }^{6}$ was used to quantify total number of counts for each gene.

1.9.2 RNA-Seq analysis: Differential gene expression (DGE) analysis using a within and between subject design was performed with DESeq2 ${ }^{7}$. Three days after an initial baseline saline challenge, subjects were challenged with BCG and split into three groups based on BCG concentration used $\left(10^{2}, 10^{3}\right.$, or $\left.10^{4} \mathrm{CFU}\right)$. All participants had a sample in only one concentration group, except for subject T011 $\left(10^{2}\right.$ and $\left.10^{4} \mathrm{CFU}\right)$. Comparisons were made to baseline within each group.

1.9.3 Modular analysis: Modular analysis was performed using a pre-existing framework of 260 transcriptional modules ${ }^{8}$, and we present a subset that have been functionally annotated. For each comparison and within each module, the percentage of transcripts significantly up- or down-regulated based on p-value and fold-change (FC) was calculated ( $p \leq 0.05,|\mathrm{FC}| \geq 1.5$ ), and the module score was defined as the difference in percent up or down.

1.9.4 RNA-Seq data visualization: Counts were normalized using the median-of-ratios method ${ }^{9}$ and $\log 2$ transformed for principal component analysis (PCA), hierarchical clustering, and data visualization. The transcripts of all heatmaps were hierarchically clustered using Euclidean distance and complete linkage function. The heatmaps and PCA plots were created using R v3.5.2 packages NMF ${ }^{10}$ and ggplot2 ${ }^{11}$, respectively. 


\section{References}

1. Andrews S. FastQC: A quality control tool for high throughput sequence data.

2. Martin M. Cutadapt removes adapter sequences from high-throughput sequencing reads. $20112011 ; \mathbf{1 7}(1): 3$.

3. Frankish A, Diekhans M, Ferreira AM, et al. GENCODE reference annotation for the human and mouse genomes. Nucleic Acids Res 2019; 47(D1): D766-D73.

4. Kim D, Langmead B, Salzberg SL. HISAT: a fast spliced aligner with low memory requirements. Nat Methods 2015; 12(4): 357-60.

5. Li H, Handsaker B, Wysoker A, et al. The Sequence Alignment/Map format and SAMtools. Bioinformatics 2009; 25(16): 2078-9.

6. Liao Y, Smyth GK, Shi W. featureCounts: an efficient general purpose program for assigning sequence reads to genomic features. Bioinformatics 2014; 30(7): 923-30.

7. Love MI, Huber W, Anders S. Moderated estimation of fold change and dispersion for RNA-seq data with DESeq2. Genome Biol 2014; 15(12): 550.

8. Chaussabel D, Baldwin N. Democratizing systems immunology with modular transcriptional repertoire analyses. Nat Rev Immunol 2014; 14(4): 271-80.

9. Anders S, Huber W. Differential expression analysis for sequence count data. Genome Biol 2010; 11(10): R106.

10. Gaujoux R, Seoighe C. A flexible R package for nonnegative matrix factorization. BMC Bioinformatics 2010; 11: 367. 
11. Wickham H. ggplot2: Elegant Graphics for Data Analysis; 2016. 
Table S1: Stratification of anticipated adverse events experienced by participants in the different susceptibility groups at different timepoint following lung challenge.

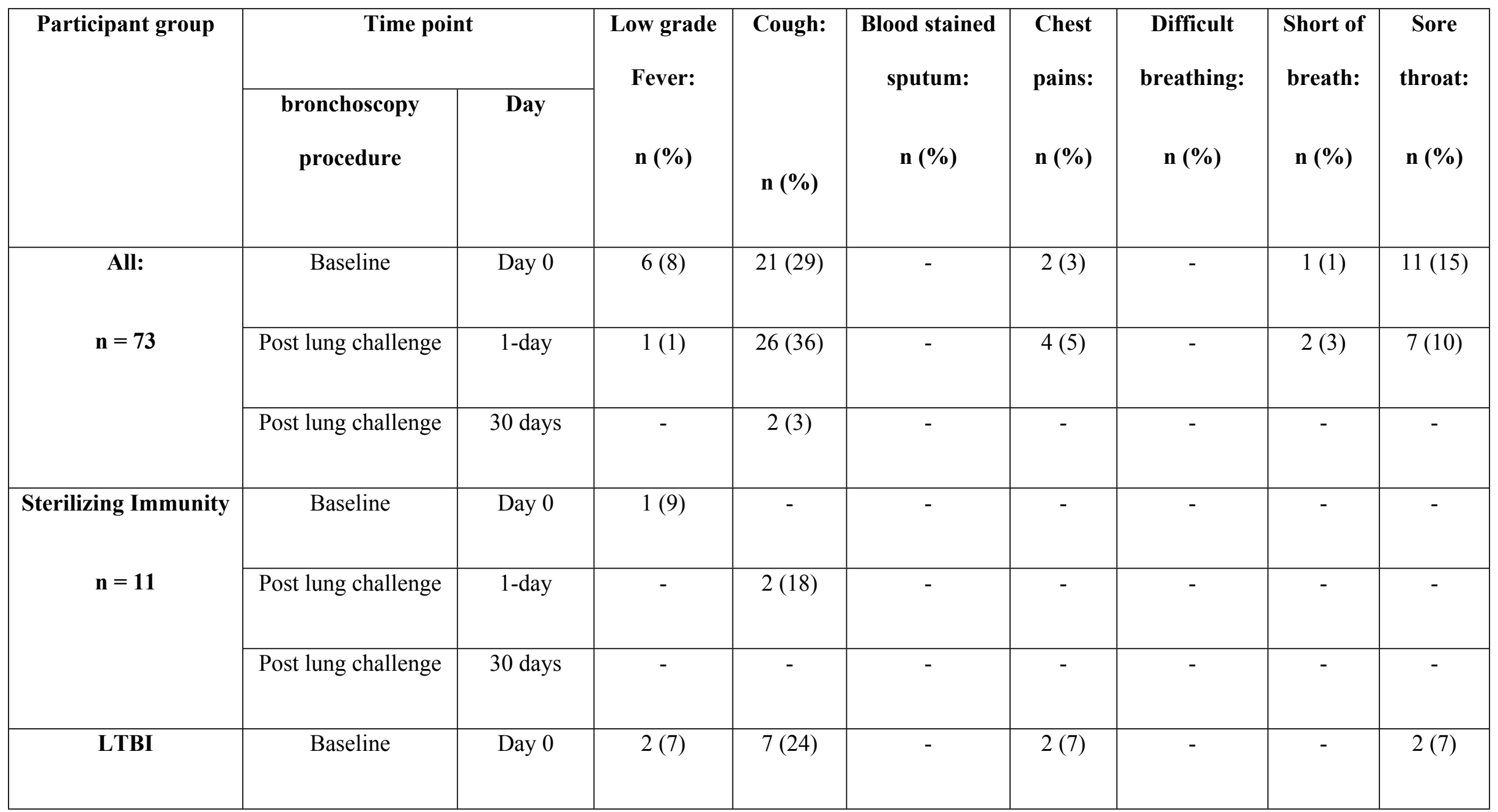




\begin{tabular}{|c|c|c|c|c|c|c|c|c|c|}
\hline & Post lung challenge & 1-day & - & $7(24)$ & - & $1(3)$ & - & - & $2(7)$ \\
\hline $\mathbf{n}=\mathbf{2 9}$ & Post lung challenge & 30 days & - & - & - & - & - & - & - \\
\hline Previous TB & Baseline & Day 0 & $2(8)$ & $11(44)$ & - & - & - & $1(4)$ & $8(32)$ \\
\hline \multirow[t]{2}{*}{$\mathrm{n}=\mathbf{2 5}$} & Post lung challenge & 1-day & - & $13(52)$ & - & $3(12)$ & - & $2(8)$ & $4(16)$ \\
\hline & Post lung challenge & 30 days & - & $2(8)$ & - & - & - & - & - \\
\hline Recurrent TB & Baseline & Day 0 & $1(13)$ & $3(38)$ & - & - & - & - & $1(13)$ \\
\hline \multirow[t]{2}{*}{$\mathbf{n}=\mathbf{8}$} & Post lung challenge & 1-day & $1(13)$ & $4(50)$ & - & - & - & - & $1(13)$ \\
\hline & Post lung challenge & 30 days & - & - & - & - & - & - & - \\
\hline
\end{tabular}


Table S2: BCG culture results performed on BAL fluid retrieved from the BCG challenged lung segment after 3 days post instillation in the different TB susceptibility groups. A 10ml aliquot of BAL fluid was cultured using the Mycobacterial-Growth-In-Tube liquid culture system.

\begin{tabular}{|c|c|c|c|c|c|}
\hline Participant groups & $\begin{array}{c}\text { Number of } \\
\text { participants } \\
\text { with BCG } \\
\text { culture results }\end{array}$ & BCG dose & $\begin{array}{c}\text { BCG culture } \\
\text { negative } \\
\text { n (\%) }\end{array}$ & $\begin{array}{c}\text { BCG culture } \\
\text { positive } \\
\text { n (\%) }\end{array}$ & $\begin{array}{c}\text { Time to } \\
\text { positivity } \\
\text { (Mean in } \\
\text { days) }\end{array}$ \\
\hline All & 54 & $\begin{array}{l}1\left(10^{2} \mathrm{CFU}\right) \\
2\left(10^{3} \mathrm{CFU}\right) \\
52\left(10^{4} \mathrm{CFU}\right)\end{array}$ & $49(91)$ & $5(9)$ & 22 \\
\hline $\begin{array}{l}\text { Sterilizing } \\
\text { immunity }\end{array}$ & 7 & $\begin{array}{l}0\left(10^{2} \mathrm{CFU}\right) \\
0\left(10^{3} \mathrm{CFU}\right) \\
7\left(10^{4} \mathrm{CFU}\right)\end{array}$ & $6(86)$ & $1(14)$ & 23 \\
\hline Latent TB infection & 25 & $\begin{array}{l}0\left(10^{2} \mathrm{CFU}\right) \\
0\left(10^{3} \mathrm{CFU}\right) \\
25\left(10^{4} \mathrm{CFU}\right)\end{array}$ & $23(92)$ & $2(8)$ & 25 \\
\hline Previous TB & 13 & $\begin{array}{l}0\left(10^{2} \mathrm{CFU}\right) \\
2\left(10^{3} \mathrm{CFU}\right)\end{array}$ & $13(100)$ & $0(0)$ & $\mathrm{n} / \mathrm{a}$ \\
\hline
\end{tabular}




\begin{tabular}{|l|c|c|c|c|c|}
\hline & & $11\left(10^{4} \mathrm{CFU}\right)$ & & \\
\hline Recurrent TB & 9 & $0\left(10^{2} \mathrm{CFU}\right)$ & $7(78)$ & $2(22)$ & 19 \\
& & $0\left(10^{3} \mathrm{CFU}\right)$ & & & \\
& & $9\left(10^{4} \mathrm{CFU}\right)$ & & & \\
\hline
\end{tabular}


A

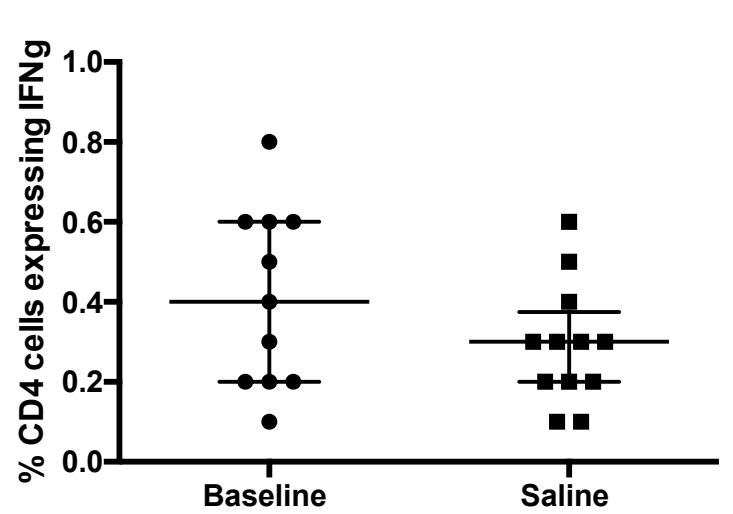

C

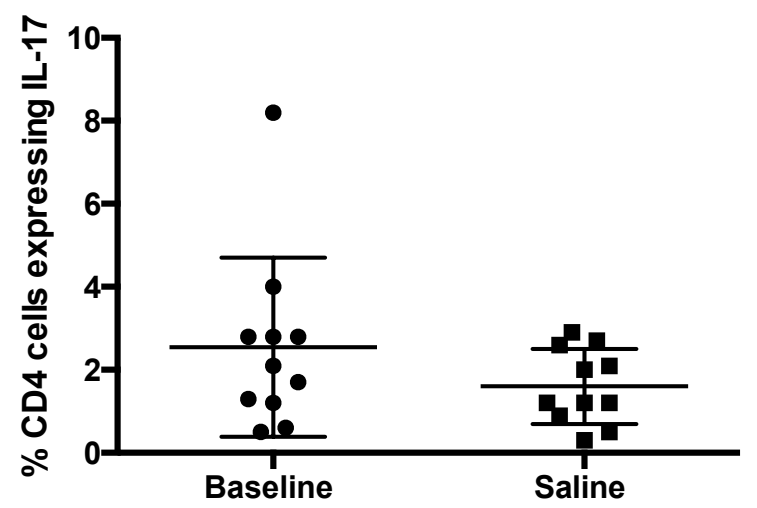

B

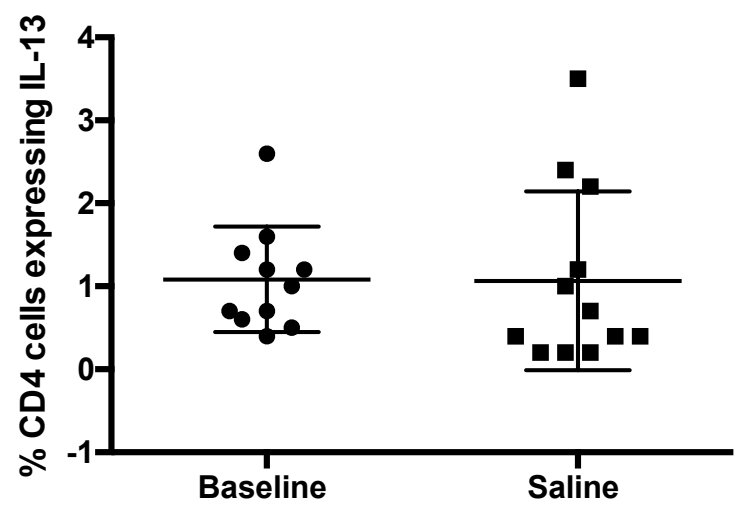

D

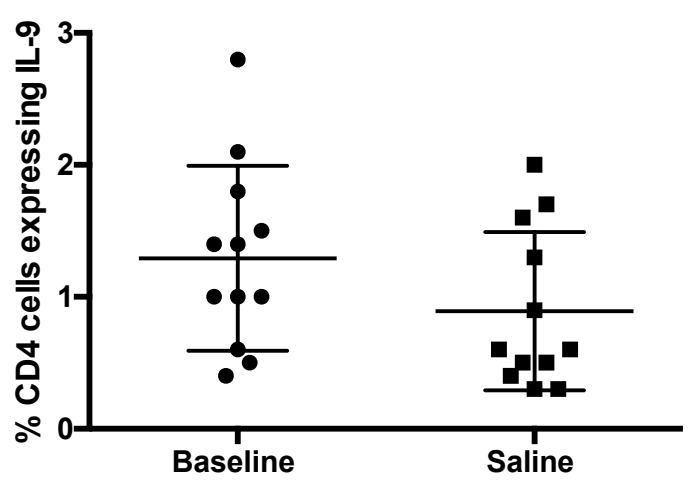

Figure S1: Cytokine expression by CD4 T cells isolated from broncho-alveolar lavage

fluid (BALF) recovered from the saline only control segments in participants challenged with BCG and PPD. (A) level of IFN-gamma expression, (B) IL-13 expression, (C) IL-17 expression, and (D) IL-9 expression. Statistical significance was determined using the Wilcoxon matched-pairs signed rank. * indicates $\mathrm{p}<0.05$. (No significance was observed). 
A

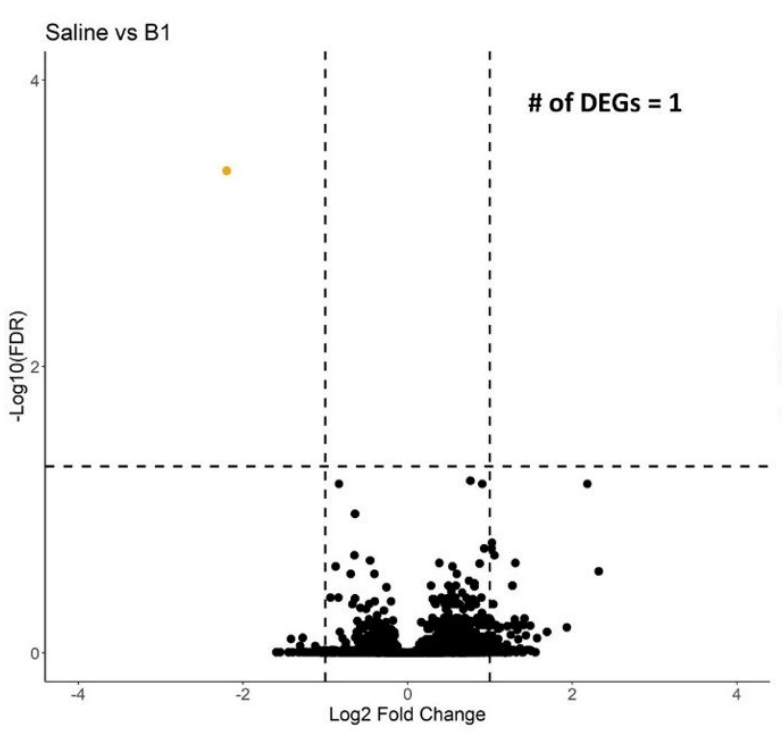

C

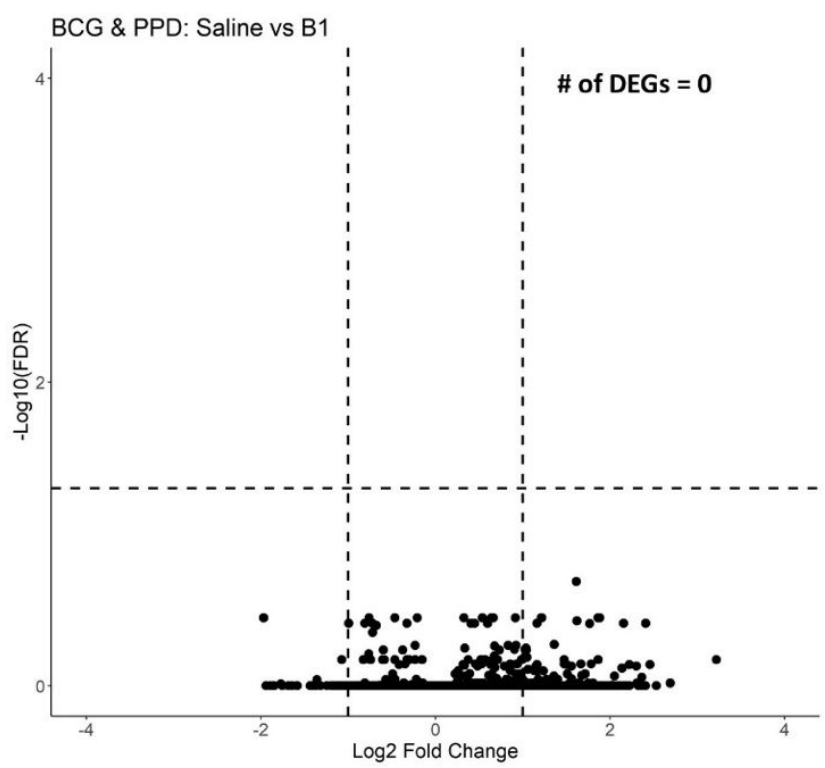

B

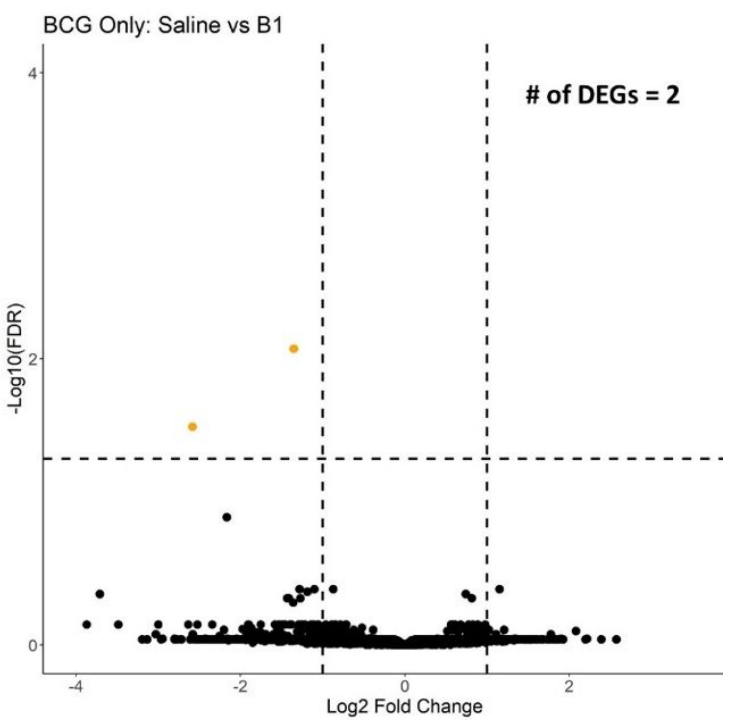

Figure S2. RNA expression in broncho-alveolar lavage (BAL) cells recovered from the saline only control segments in participants challenged with BCG alone or together with PPD in different lung segments. Transcriptomic analysis of BAL cells using RNAseq represented as volcano plots showing the differentially expressed genes (DEGs) in the saline only segment compared to pre-challenge baseline (B1) in previous TB participants and expressed as a Log2 fold change. Data is shown for (A) all participants (n=17) (B) participants who only received BCG lung challenge $(n=6)$ and $(C)$ participants who received both $B C G$ and PPD $(n=11)$. Yellow dots indicate DEGs with Log2 fold change $\geq 1$ (horizontal dashed lines) and an FDR of $<0.05$ after multiple comparison corrections (vertical dashed lines). The number of DEGs meeting these criteria are indicated in each volcano plot. 
A

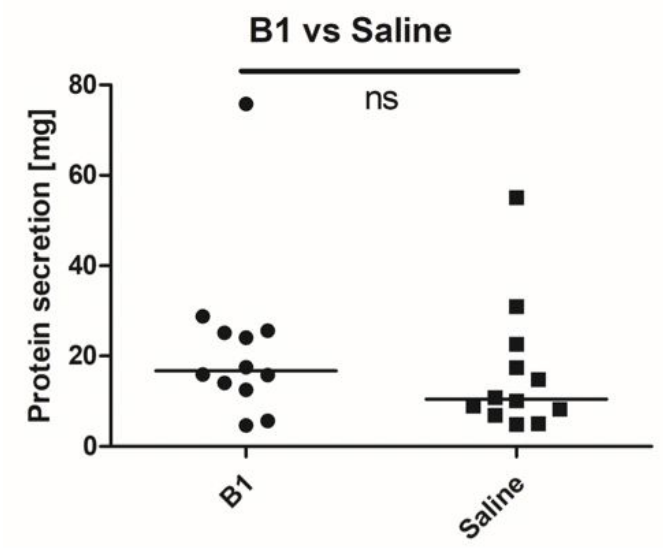

C

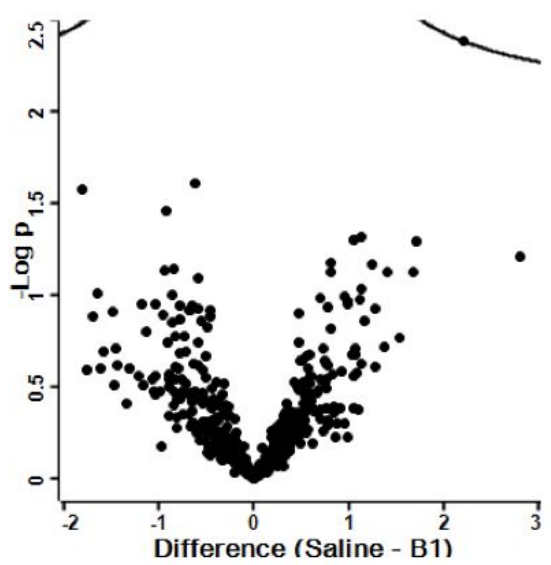

B

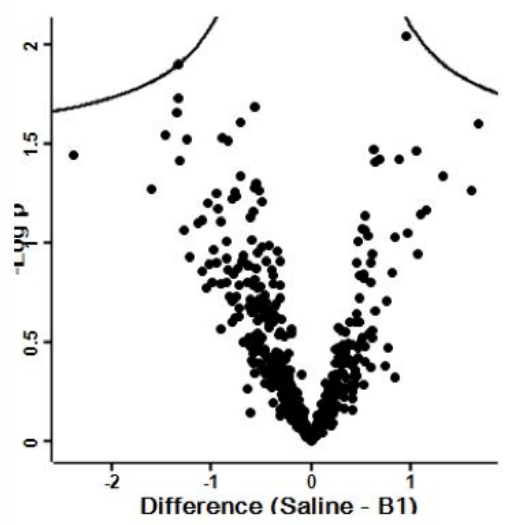

D

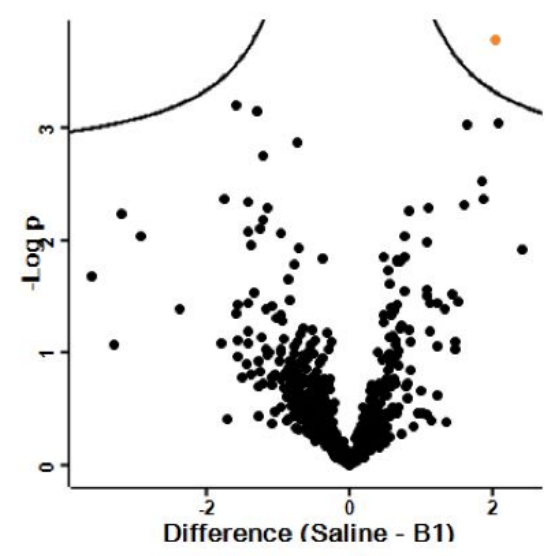

Figure S3: Protein expression in broncho-alveolar lavage (BAL) supernatant recovered from the saline only control segments in participants challenged with BCG alone or together with PPD in different lung segments. (A) Total protein (in $\mathrm{mg}$ ) measured using BCA assay in BAL supernatants from the saline control segment and compared to the pre-challenge bronchoscopy (B1). (B-D) Proteomic analysis of BAL supernatants using mass spectrometry and represented as volcano plots showing the abundance of individual proteins in the saline only segment compared to pre-challenge baseline (B1) in previous TB participants. Data is shown for (B) all participants $(n=12)(C)$ participants who only received BCG lung challenge $(n=6)$ and (D) participants who received both $\mathrm{BCG}$ and PPD $(\mathrm{n}=6)$. Permutation-based multiple testing correction was performed. Proteins that survived the threshold of FDR $=0.05$ and $\mathrm{S}_{0}=0.1$ are highlighted in orange and are considered statistically significant (No significance was observed). 


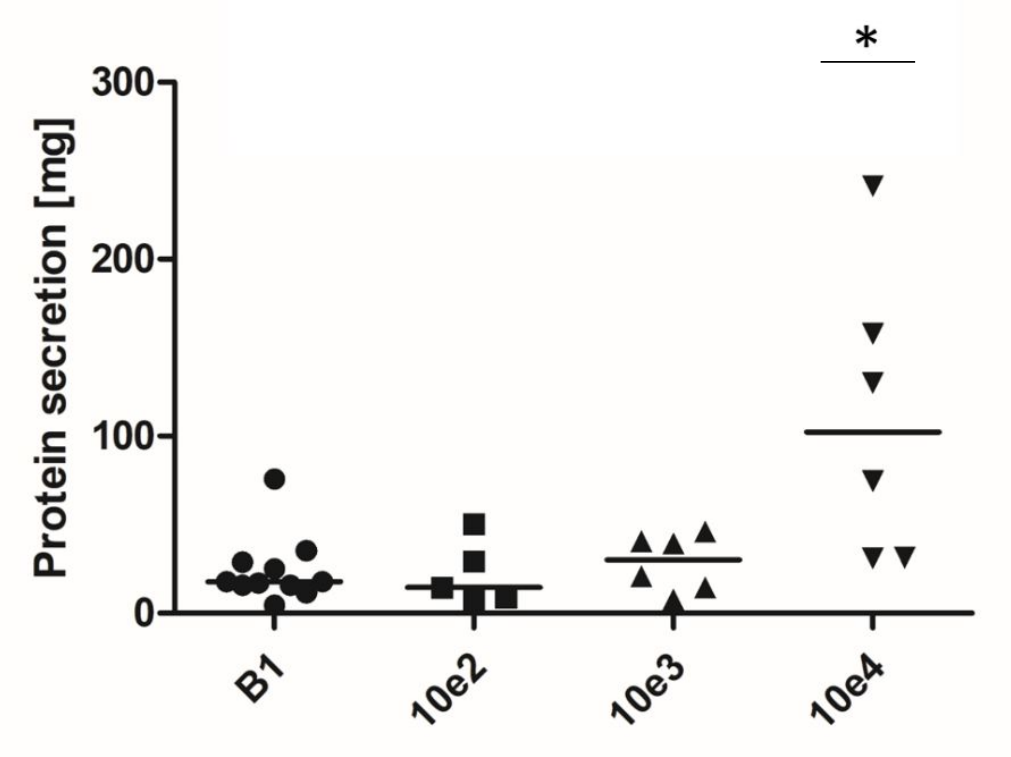

Figure S4: Total protein amount in broncho-alveolar lavage (BAL) supernatant obtained from the BCG challenged lung segment in participants challenged with different concentrations of BCG. Total protein was measured using the BCA assay. Statistical significance was determined using Kruskal-Wallis test followed by Dunn’s Multiple Comparisons test. * indicates $\mathrm{p}<0.05$ 

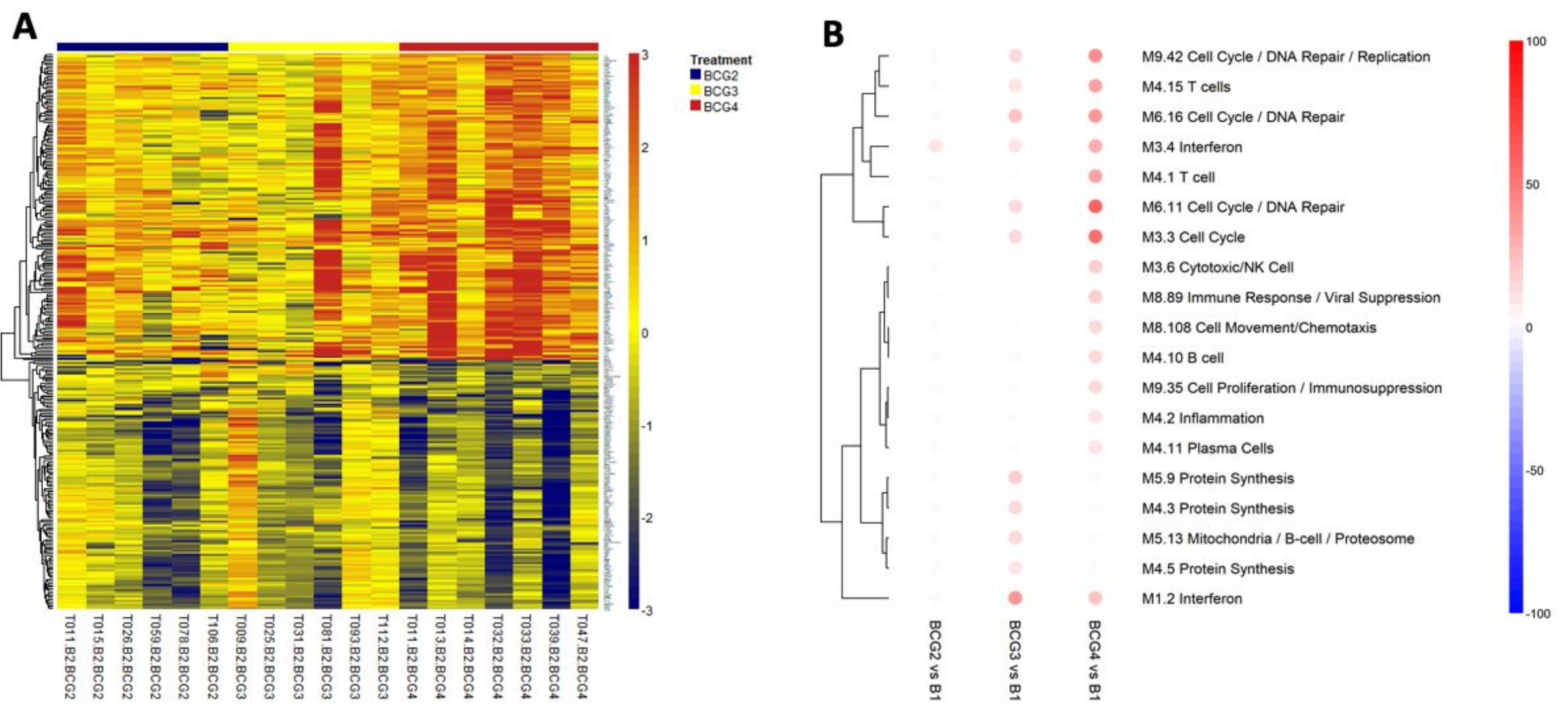

Figure S5: Transcriptomic changes from baseline induced by different concentrations of BCG challenge. (A) Baseline subtracted heatmap of 281 differentially expressed genes that survived FDR $<0.05$ and $|\mathrm{FC}|>2$ in BCG 10e4 vs baseline comparison. (B) Modular map showing the difference in percent of genes within a module significantly up- vs down-regulated for each concentration. Significance was determined by the threshold $\mathrm{p}<0.05$ and $|\mathrm{FC}|>1.5$. 
Table S3: Transcriptomic analysis showing the top differentially expressed genes (DEGs) post BCG (104, 103, and $102 \mathrm{CFU})$.

\section{$10^{4}$ CFU BCG: Top 10 differentially expressed genes}

\begin{tabular}{|c|c|c|c|c|c|}
\hline & e Symbol & mean & fold change & lue & sted p-value \\
\hline G00000108700 & 8 & 7 & & E-07 & 223145 \\
\hline G00000212579 & 5561 & 9 & & E-05 & 1483548 \\
\hline G00000229961 & 57143.1 & & & E-06 & $\$ 158399$ \\
\hline G00000104921 & $\mathrm{R} 2$ & 9 & & E-06 & 394647 \\
\hline G00000164509 & RA & & & E-05 & 826461 \\
\hline G00000108688 & 7 & & & 0650516 & $\$ 039121$ \\
\hline G00000229754 & R2P1 & 4 & & E-07 & 20609 \\
\hline G00000138061 & 1B1 & 4 & & E-06 & 643862 \\
\hline G00000253838 & 07991.2 & p & & E-05 & 7493106 \\
\hline G00000239961 & R4 & & & $\$ 405156$ & 1850357 \\
\hline
\end{tabular}

10³ CFU BCG: Differentially expressed genes

\begin{tabular}{|l|l|l|l|l|l|}
\hline & f Symbol & mean & fold change & lue & sted p-value \\
\hline G00000121807 & 2 & $\$ 6$ & & & \\
& & & & & \\
\hline
\end{tabular}


$10^{2}$ CFU BCG: Differentially expressed genes

\begin{tabular}{|l|l|l|l|r|r|}
\hline & fymbol & mean & fold change & lue & \\
\hline G00000185303 & PA2 & & & $1,37 \mathrm{E}-09$ & $2,93 \mathrm{E}-05$ \\
\hline $\mathbf{G 0 0 0 0 0 1 6 8 8 7 8}$ & PB & & & $5,59 \mathrm{E}-08$ & 0,000595155 \\
\hline $\mathbf{G 0 0 0 0 0 0 1 0 3 2 7}$ & B1 & 21 & & $1,28 \mathrm{E}-07$ & 0,000905828 \\
\hline
\end{tabular}


Table S4: Mass spectrometry analysis showing the top secreted proteins post BCG $\left(10^{4}, 10^{3}\right.$, and $\left.10^{2} \mathrm{CFU}\right)$ as compared to baseline bronchoscopy.

\begin{tabular}{|c|c|c|c|c|c|}
\hline \multicolumn{6}{|c|}{ 104 CFU BCG: Top secreted proteins } \\
\hline Majority protein IDs & Protein names & Gene names & Significant & $\begin{array}{l}\text { Difference } \\
\text { (10e4-B1) }\end{array}$ & $\begin{array}{c}-\log \\
\text { (p-value) }\end{array}$ \\
\hline $\begin{array}{l}\text { A0A087WYT0; A0A087WV42; } \\
\text { A0A087WZY1; A0A087WYF5; } \\
\text { A0A0A0MT31; P02810 }\end{array}$ & $\begin{array}{l}\text { Salivary acidic proline-rich phosphoprotein } 1 / 2 \text {; Salivary } \\
\text { acidic proline-rich phosphoprotein } 1 / 2 \text {; Salivary acidic } \\
\text { proline-rich phosphoprotein } 3 / 4 \text {; Peptide P-C }\end{array}$ & PRH1 & + & $-4,28$ & 1,63 \\
\hline P61626; F8VV32; A0A0B4J259 & Lysozyme C;Lysozyme & LYZ & + & $-3,65$ & 3,09 \\
\hline A0A087WY73; Q16378 & Proline-rich protein 4 & PRR4 & + & $-3,46$ & 1,83 \\
\hline P80723 & Brain acid soluble protein 1 & BASP1 & + & $-3,13$ & 2,11 \\
\hline P62328 & Thymosin beta-4; Hematopoietic system regulatory peptide & TMSB4X & + & $-2,94$ & 1,64 \\
\hline Q13740;F5GXJ9 & CD166 antigen & ALCAM & + & $-2,85$ & 1,88 \\
\hline
\end{tabular}




\begin{tabular}{|c|c|c|c|c|}
\multirow{2}{*}{ P04745; P19961; P04746 } & Alpha-amylase 1; Alpha-amylase 2B; Pancreatic alpha- & AMY1A; AMY2B; & $+2,64$ & 2,65 \\
& amylase & SCGB1A1 & + & $-2,59$ \\
\hline P11684 & Uteroglobin & 1,69 & $+2,50$ \\
\hline Q96S96 & Phosphatidylethanolamine-binding protein 4 & PEBP4 & $+2,15$ \\
\hline
\end{tabular}

\begin{tabular}{|c|c|c|c|c|c|}
\hline \multicolumn{6}{|c|}{ 10² CFU BCG: Top secreted proteins } \\
\hline Majority protein IDs & Protein names & Gene names & Significant & $\begin{array}{l}\text { Difference } \\
\text { (10e2-B1) }\end{array}$ & $\begin{array}{l}-\log (p- \\
\text { value) }\end{array}$ \\
\hline $\begin{array}{l}\text { Q16777; Q6FI13; } \\
\text { A0A0U1RR32; A0AOU1RRH7; } \\
\text { Q99878; Q96KK5; Q9BTM1; } \\
\text { P20671; P0C0S8; HOYFX9 }\end{array}$ & $\begin{array}{l}\text { Histone H2A type 2-C; Histone H2A type 2-A; Histone } \\
\text { H2A type 1-J; Histone H2A type 1-H; Histone H2A.J; } \\
\text { Histone H2A type 1-D; Histone H2A type 1; Histone } \\
\text { H2A }\end{array}$ & $\begin{array}{l}\text { HIST2H2AC; } \\
\text { HIST2H2AA3; } \\
\text { HIST1H2AJ; } \\
\text { HIST1H2AH;H2AFJ; } \\
\text { HIST1H2AD; } \\
\text { HIST1H2AG }\end{array}$ & + & 2,72 & 5,30 \\
\hline
\end{tabular}

